San Jose State University

SJSU ScholarWorks

Mineta Transportation Institute Publications

$11-2019$

\title{
Moving from Walkability? Evaluation Traditional and Merging Data Sources for Evaluating Changes in Campus-Generated Greenhouse Gas Emissions
}

\author{
Troy Kawahara \\ California Polytechnic State University, San Luis Obispo \\ Bo Liu \\ University of California, Los Angeles \\ Anurag Pande \\ California Polytechnic State University, San Luis Obispo \\ Calvin Thigpen \\ Lime \\ Carole Turley Voulgaris \\ California Polytechnic State University, San Luis Obispo
}

Follow this and additional works at: https://scholarworks.sjsu.edu/mti_publications

Part of the Environmental Engineering Commons, and the Transportation Engineering Commons

\section{Recommended Citation}

Troy Kawahara, Bo Liu, Anurag Pande, Calvin Thigpen, and Carole Turley Voulgaris. "Moving from Walkability? Evaluation Traditional and Merging Data Sources for Evaluating Changes in CampusGenerated Greenhouse Gas Emissions" Mineta Transportation Institute Publications (2019).

https://doi.org/10.31979/mti.2019.1857

This Report is brought to you for free and open access by SJSU ScholarWorks. It has been accepted for inclusion in Mineta Transportation Institute Publications by an authorized administrator of SJSU ScholarWorks. For more information, please contact scholarworks@sjsu.edu. 


\section{SJSU}

\section{MTI//}

Moving from Walkability? Evaluation Traditional and

Merging Data Sources for Evaluating Changes in

Campus-Generated Greenhouse Gas Emissions

Troy Kawahara

Bo Liu

Anurag Pande, PhD
Calvin Thigpen, PhD

Carole Turley Voulgaris, PhD

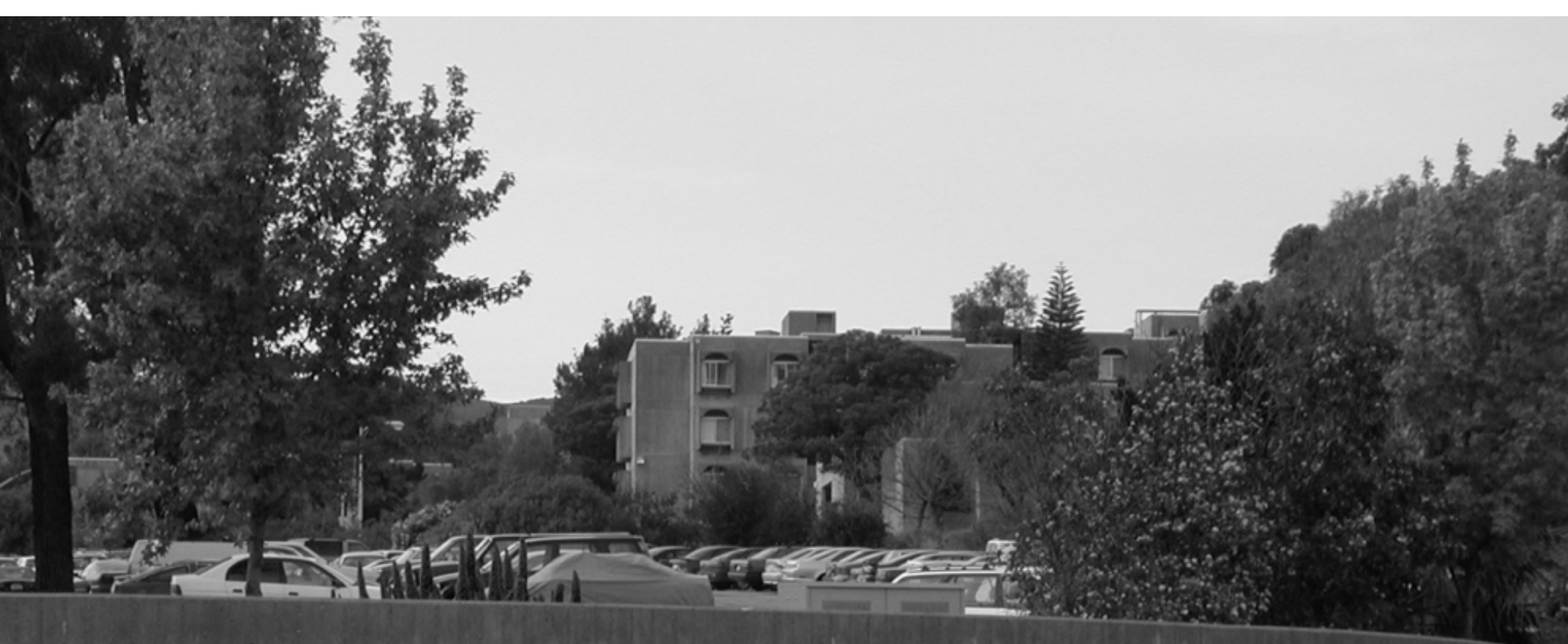

CALIFORNIA POLYTECHNIC
SAN LUIS OBISPO

CsuTc California State University
Transportation Consortium

CAL POLY 


\section{MINETA TRANSPORTATION INSTITUTE}

Founded in 1991, the Mineta Transportation Institute (MTI), an organized research and training unit in partnership with the Lucas College and Graduate School of Business at San José State University (SJSU), increases mobility for all by improving the safety, efficiency, accessibility, and convenience of our nation's transportation system. Through research, education, workforce development, and technology transfer, we help create a connected world. MTI leads the four-university. MTI leads the four-university California State University Transportation Consortium funded by the State of California through Senate Bill I.

MTl's transportation policy work is centered on three primary responsibilities:

\section{Research}

MTI works to provide policy-oriented research for all levels of government and the private sector to foster the development of optimum surface transportation systems. Research areas include: bicycle and pedestrian issues; financing public and private sector transportation improvements; intermodal connectivity and integration; safety and security of transportation systems; sustainability of transportation systems; transportation / land use / environment; and transportation planning and policy development. Certified Research Associates conduct the research. Certification requires an advanced degree, generally a Ph.D., a record of academic publications, and professional references. Research projects culminate in a peer-reviewed publication, available on TransWeb, the MTI website (http://transweb.sjsu.edu).

\section{Education}

The Institute supports education programs for students seeking a career in the development and operation of surface transportation systems. MTI, through San José State University, offers an AACSBaccredited Master of Science in Transportation Management and graduate certificates in Transportation Management, Transportation Security, and High-Speed Rail Management that serve to prepare the nation's transportation managers for the 2 Ist century. With the active assistance of the California Department of Transportation (Caltrans), MTI delivers its classes over a state-of-the-art videoconference network throughout the state of California and via webcasting beyond, allowing working transportation professionals to pursue an advanced degree regardless of their location. To meet the needs of employers seeking a diverse workforce, MTl's education program promotes enrollment to under-represented groups.

\section{Information and Technology Transfer}

MTI utilizes a diverse array of dissemination methods and media to ensure research results reach those responsible for managing change. These methods include publication, seminars, workshops, websites, social media, webinars, and other technology transfer mechanisms. Additionally, MTI promotes the availability of completed research to professional organizations and journals and works to integrate the research findings into the graduate education program.MTl's extensive collection of transportation- related publications is integrated into San José State University's world-class Martin Luther King, Jr. Library.

\section{Disclaimer}

The contents of this report reflect the views of the authors, who are responsible for the facts and accuracy of the information presented herein. This document is disseminated in the interest of information exchange. The report is funded, partially or entirely, by a grant from the State of California. This report does not necessarily reflect the official views or policies of the State of California or the Mineta Transportation Institute, who assume no liability for the contents or use thereof. This report does not constitute a standard specification, design standard, or regulation. 
REPORT 19-27

\title{
MOVING FROM WALKABILITY?
}

\section{EVALUATION TRADITIONAL AND EMERGING DATA SOURCES FOR EVALUATING CHANGES IN CAMPUS-GENERATED GREENHOUSE GAS EMISSIONS}

\author{
Troy Kawahara \\ Bo Liu \\ Anurag Pande, PhD \\ Calvin Thigpen, $\mathrm{PhD}$ \\ Carole Turley Voulgaris, PhD
}

October 2019

DOI: $10.31979 / \mathrm{mti} .2019 .1857$

A publication of

Mineta Transportation Institute

Created by Congress in 1991

College of Business

San José State University

San José, CA 95192-0219 


\section{TECHNICAL REPORT DOCUMENTATION PAGE}

1. Report No. 19-27

4. Title and Subtitle

Moving from Walkability? Evaluation Traditional and Merging Data Sources for Evaluating Changes in Campus-Generated Greenhouse Gas Emissions

2. Government Accession No.
3. Recipient's Catalog No.

5. Report Date

October 2019

6. Performing Organization Code

8. Performing Organization Report CA-MTI-1857
7. Authors

Troy Kawahara (no ORCID)

Bo Liu (ORCID: 0000-0002-4636-5254)

Anurag Pande (ORCID: 0000-0002-3456-7932)

Calvin Thigpen (ORCID: 0000-0003-4284-2882)

Carole Turley Voulgaris (ORCID: 0000-0003-0556-924X)

9. Performing Organization Name and Address

Mineta Transportation Institute

College of Business

San José State University

San José, CA 95192-0219

12. Sponsoring Agency Name and Address

State of California SB1 2017/2018

Trustees of the California State University

Sponsored Programs Administration

401 Golden Shore, 5th Floor

Long Beach, CA 90802

\section{Work Unit No.}

11. Contract or Grant No.

13. Type of Report and Period Covered ZSB12017-SJAUX

14. Sponsoring Agency Code

Final Report

15. Supplemental Notes

\section{Abstract}

Universities are increasingly committing to reduce campus-generated greenhouse gas emissions, whether voluntarily or in response to a legal mandate. As an initial step to keeping these commitments, universities need an accounting of baseline greenhouse gas emissions levels and means of monitoring changes in campus-generated greenhouse gas emissions over time. Commute-generated greenhouse gas emissions from travel to and from campus by students and employees are among the most difficult to quantify. This report examines some of the challenges associated with estimating campus-generated greenhouse gas emissions and evaluates ways to address those challenges. The purpose of this study is to identify changes in campus-generated travel behavior at California Polytechnic State University based on the results of three successive campus-wide travel surveys; to evaluate alternative data sources that have the potential to supplement or replace campus travel surveys as a source of data for campus-generated greenhouse gas emissions; and to evaluate alternate methods to estimating greenhouse gas emissions from campus-generated vehicle miles traveled, depending on the presence of campus-specific information about vehicle fleet characteristics. The results of successive travel surveys suggest that the campus population has become more car-dependent over time. Comparison of survey results with data collected from automating traffic counting devices and mobile device data suggest that surveys that are limited to members of the campus community are likely to undercount campus-generated vehicle miles traveled by excluding infrequent, but potentially long, trips by campus visitors. Finally, we find that using campus-specific information on the model years of vehicles used to commute to campus yields higher estimates of campus-generated greenhouse gas emissions, relative to average regional emissions rates.

\section{Key Words}

Persons and Personal Characteristics, Planning, Traffic measurement, Transportation modes, Vehicle characteristics

19. Security Classif. (of this report) Unclassified

\section{Distribution Statement}

No restrictions. This document is available to the public through The National Technical Information Service, Springfield, VA 22161

20. Security Classif. (of this page)

Unclassified
21. No. of Pages

51
22. Price 


\title{
Copyright () 2019 \\ by Mineta Transportation Institute \\ All rights reserved
}

\author{
Mineta Transportation Institute \\ College of Business \\ San José State University \\ San José, CA 95192-0219
}

Tel: (408) 924-7560

Fax: (408) 924-7565

Email: mineta-institute@sjsu.edu

transweb.sjsu.edu 


\section{ACKNOWLEDGMENTS}

The authors would like to thank Dennis Elliot, Kylee Singh, and Eric Veium of Cal Poly Facilities and Cheryl Andrus and Marlene Cramer of Cal Poly Transportation and Parking Services for their assistance facilitating on-campus data collection and survey administration.

We thank StreetLight data for providing access to their data platform.

We also thank the following Cal Poly students for their assistance with data collection and background research: Jill Shinn, Isela Dy, Vidhi Sachdeva, and Aria Haghnia.

The authors thank Editing Press, for editorial services, as well as MTI staff, including Executive Director Karen Philbrick, PhD; Deputy Executive Director Hilary Nixon, PhD; Graphic Designer Alverina Eka Weinardy; and Executive Administrative Assistant Jill Carter.

Cover photo by Arthaey Angosii (https://www.flickr.com/photos/arthaey/). Licensed under Creative Commons. 


\section{TABLE OF CONTENTS}

$\begin{array}{ll}\text { Executive Summary } & 4\end{array}$

$\begin{array}{ll}\text { I. Introduction } & 5\end{array}$

$\begin{array}{ll}\text { Motivation } & 5\end{array}$

$\begin{array}{ll}\text { Project Objectives } & 6\end{array}$

$\begin{array}{ll}\text { Report Organization } & 6\end{array}$

$\begin{array}{ll}\text { II. Changes in Campus Travel } & 7\end{array}$

Data $\quad 7$

Usual Commute Mode to Campus $\quad 12$

Commute Distance $\quad 21$

Campus Trip Generation $\quad 22$

Commute-Generated Vehicle miles traveled 24

Conclusion $\quad 24$

III. Comparison of Alternative Travel Data Sources 26

$\begin{array}{ll}\text { Background } & 26\end{array}$

Data Collection Details $\quad 28$

$\begin{array}{ll}\text { Results } & 29\end{array}$

IV. Estimating Greenhouse Gas Emission from Vehicle Miles Traveled 36

$\begin{array}{ll}\text { Methods and Data } & 36\end{array}$

$\begin{array}{ll}\text { Results and Discussion } & 37\end{array}$

$\begin{array}{ll}\text { V. Conclusion } & \mathbf{4 0}\end{array}$

Summary of Findings and Suggestions for Future work 40

$\begin{array}{ll}\text { Abbreviations and Acronyms } & 41\end{array}$

$\begin{array}{ll}\text { Endnotes } & 42\end{array}$

$\begin{array}{ll}\text { Bibliography } & 47\end{array}$

About the authors $\quad 53$

$\begin{array}{ll}\text { Peer Review } & 54\end{array}$ 


\section{LIST OF FIGURES}

1. Usual Mode Shares of Student and Employee Trips to and from Campus

2. Within-Cohort Changes in Drive Alone Mode Shares, 2015-2019

3. Between-Cohort Differences in Drive Alone Mode Shares, 2015-2019

4. Within-Cohort Changes in Walking Mode Shares, 2015-2019

5. Between-cohort differences in walking mode shares, 2015-2019

6. Within-Cohort Changes in Bicycle Mode Shares, 2015-2019

7. Between-Cohort Differences in Bicycle Mode Shares, 2015-2019

8. Within-Cohort Changes in Transit Mode Shares, 2015-2019

9. Between-Cohort Differences in Transit Mode Shares, 2015-2019

10. Within-Cohort Changes in Carpool Mode Shares, 2015-2019

11. Between-Cohort Differences in Transit Mode Shares, 2015-2019

12. Change in Average Commute Distance for Students and Employees, 2018-2019 21

13. Within-Cohort Changes in Average Commute Distance, 2018-2019

14. Between-Cohort Differences in Average Commute Distance, 2018-2019

15. Change in Weekly Round Trips to Campus for Students and Employees, 2018-2019

16. Within-Cohort Changes in Weekly Round Trips to Campus, 2018-2019

17. Between-Cohort Differences in Weekly Round Trips to Campus, 2018-2019

18. Approximate Positioning of the PTCs

19. Location of SLD “Zones” or Screen Line

20. Screen Capture of the SLD Zone Mapping Interface

21. Relationship Between PTC and SLD Data Estimates

22. Proportional Trip Length Distribution at California Boulevard 
23. Proportional Trip Length Distribution at Grand Avenue

24. Proportional Trip Length Distribution at Highland Dr.

25. VMT Breakdowns for Non-PEV Light-Duty Vehicles by Vehicle Model Year

26. GHG Emissions Estimation by the Method 


\section{LIST OF TABLES}

1. Survey Dates and Response Rates 9

2. Travel Survey Response Summary 31

3. Comparison of Total Trip Generation Values By Data Source 31

4. Comparison of Total Trip Generation Values by Data Source 33

5. Estimated VMT

6. Comparative Campus Characteristics of Select Universities with Publicly Available VMT Estimates 


\section{EXECUTIVE SUMMARY}

In this study, we analyzed data from three successive campus travel surveys in order to estimate the effect of University campus population and policy changes (e.g., parking restrictions) on campus mode shares and campus-generated vehicle miles traveled. We also compared survey-based travel data to other sources of transportation data, such as vehicle counts and mobile device data. Finally, we compared alternative methods for estimating greenhouse gas emissions from travel survey data.

Based on the analysis of survey data, the total vehicle miles traveled was 53.63 million vehicle miles, with $98.7 \%$ from gas-powered cars and trucks, $0.6 \%$ from electric cars and trucks, and the remaining 0.7 percent from motorcycles. However, comparison with mobile device data (provided by Street Light Inc.) highlights the problem that the survey's emphasis on commute trips (those that occur at least weekly) neglects infrequent, but long $(100+$ miles), trips made by visitors/invited guests to campus.

Results from successive surveys suggest that cohorts of students (e.g., the class of 2018, who were first-year students at the time of the 2015 survey, and fourth-year students at the time of the 2018 survey) become more car-dependent and moved further from campus as they age, i.e., from their first year to their fourth year (note that this was not a true panel survey: successive surveys sampled from overlapping populations, but did not include identical groups of survey respondents from each cohort). This effect would not necessarily result in increases in overall increases in driving over time, since the oldest, most car-dependent group (fourth-year students) graduates each year as a less cardependent group (first-year students) arrives. However, the results of successive surveys also suggest that younger cohorts of students (e.g. the class of 2021 relative to the class of 2020) are increasingly car-dependent. For example, second-year students in 2019 had about the same commute distances on average as did the previous year's class of secondyear students, but they were more than 30 percent more likely to drive alone to campus.

The share of first-year students driving alone to and from campus was reduced by a restriction for first-year students on on-campus parking. Based on studies suggesting that experience with alternatives to driving alone makes people less car-dependent later in life, it was expected that this first-year reduction in driving might persist into students' second year, even after the restriction on on-campus parking was lifted. However, this was not the case. In fact, second- and third-year students in 2019 were more likely to drive alone to campus than second- and third-year students in 2018 were.

Total GHG emissions were estimated using two separate approaches. The first used aggregated emission factors, and the second used emission factors that had been disaggregated by speed and vehicle model year. The disaggregated approach yielded estimated masses of equivalent carbon dioxide emissions that varied by about five percentage points higher than the aggregated approach. Regardless of the approach used, students using gas-powered vehicles are consistently found to be the largest total source of commute-related greenhouse gas emissions on campus. 


\section{INTRODUCTION}

\section{MOTIVATION}

The Greenhouse Gas Protocol divides institutional greenhouse gas (GHG) emissions into three scopes: Scope 1, Scope 2, and Scope 3. ${ }^{1}$ Scope 1 includes direct emissions by the institution, including on-site fuel combustion and emissions from vehicles the institution operates; Scope 2 includes indirect emissions from the consumption of purchased electricity; and Scope 3 includes other indirect emissions from outsourced activities and employee commuting.

A recent study has found that 52 percent of GHG emissions across Scopes 1, 2, and 3 generated by the campus of California Polytechnic State University in San Luis Obispo, hereafter referred to as Cal Poly, are from transportation sources. ${ }^{2}$ In recognition of these impacts, the university is taking several steps to reduce the vehicle miles traveled (VMT) generated by the university. These steps include: (1) traditional travel demand management (TDM) programs to encourage students, faculty, and staff to commute by alternative modes; (2) the development of student-housing facilities that incorporate elements intended to reduce dependence on travel by single-occupancy vehicles; and (3) policies restricting student parking on campus, including for on-campus housing communities. The challenges and steps being taken to address these challenges are not unique to Cal Poly. For example, in 2003, two separate studies surveyed several university campuses, finding that universities have a unique potential to encourage students, faculty, and staff to commute by active modes and by public transit. ${ }^{3}$ Since that time, researchers have described the rationale behind-and obstacles to the success ofhigher education campus travel demand management programs, such as at University of Florida, University of South Australia, and University of Connecticut. ${ }^{4}$

Several researchers have used campus travel surveys to predict or estimate the effects of such programs, including at the University of Maryland, Ohio State University, UNCCharlotte, Kent State University, California Polytechnic State University, University of California at Berkeley, University of Western Australia, Old Dominion University, and University of Southern California. ${ }^{5}$

This study builds upon those previous studies, in particularly the study completed at Cal Poly, and adds to them in two important respects. ${ }^{6}$ Firstly, while the studies cited above relied on a single cross-sectional survey, this study uses multiple surveys in order to document campus travel patterns before and after significant changes in campus parking policies and on-campus housing supply; these changes presented a natural experiment, allowing us to infer causal connections between travel behavior, policy, and the built environment, which could not have been inferred from the results of a single, crosssectional survey. Secondly, this study supplements the travel survey data with additional data sources, including a cordon count of vehicles entering and exiting campus and analysis of mobile device data. 


\section{PROJECT OBJECTIVES}

This project has three primary objectives. Firstly, it seeks to determine the effect of campus parking restrictions on campus mode shares and on campus-generated VMT, based on the results of three successive campus travel surveys. Secondly, it seeks to compare traditional survey-based travel data to other sources of transportation data, such as vehicle counts and mobile device data. Finally, it compares alternative methods for estimating greenhouse gas emissions from travel survey data.

\section{REPORT ORGANIZATION}

Chapter 1 introduced this study. Chapter 2 discusses changes in campus travel across the time period included in three successive campus travel surveys. Chapter 3 provides analysis of mobile device data in conjunction with traditional tube counts and estimates of trip patterns though survey data. Chapter 4 compares the results of alternative methods for estimating GHG emissions from the data. We report conclusions from this work and suggestions for future research in Chapter 6. 


\section{CHANGES IN CAMPUS TRAVEL}

One of the primary questions related to studying the effects of the built environment on travel behavior is the question of residential self-selection: whether people make particular transportation choices because of the characteristics of the places where they live, or whether they choose to live in particular places because it allows them to make the transportation choices they prefer. ${ }^{7}$ College campuses offer opportunities to study these questions because universities can constrain students' residential location and commute mode choices through parking and housing policies.

During the 2017/2018 academic year, California Polytechnic State University, or Cal Poly, introduced a policy prohibiting first-year students living on campus from parking on campus, severely limiting car ownership among first-year students. Smart and Klein have found that exposure to an auto-light lifestyle during early adulthood can result in lower rates of car-dependency later in life. ${ }^{8}$ This policy change thus provided a test of the question: can one year of restricted car ownership result in lower car-dependency as early as the following year?

This chapter presents our analysis of travel behavior changes across the 2014/2015, 2017/2018, and 2018/2019 academic years, among students, faculty, and staff who commute to campus, based on three campus-wide travel surveys. We examine the question of whether observed changes in travel behavior could be attributed to any of four potential explanations (which are not mutually exclusive):

1. Immediate effects of a 2018 campus parking policy change that newly prohibited first-year students living on campus from parking on campus; and

2. Lasting effects of the above policy that persist as the first year students who had been prohibited from parking on campus enter their second year.

3. Changes in the habits of the individuals commuting to and from campus (unrelated to changes in parking policy).

4. Replacement of graduating students with incoming students with different habits (unrelated to changes in parking policy).

\section{DATA}

This analysis draws on data from three campus-wide travel surveys were conducted by three different teams at Cal Poly between 2015 and 2019. The first survey was conducted for the Cal Poly Facilities office as part of the development of the campus climate action plan by Cal Poly's City and Regional Planning faculty, from June 9 to June 21, 2015. The second survey was conducted by the authors of this report as a part of this research study, from May 29 to June 8, 2018. This research study was initially intended to include a third survey during the 2018/2019 academic year, but upon learning that Walker Consultants was already planning a campus-wide transportation survey as part of their work on Cal Poly's Parking Master Plan, the authors chose to use data from that survey instead. The 
survey by Walker Consultants was conducted from January 22 to February 1, 2019. For all three surveys, invitations to participate in the survey through the SurveyMonkey platform were sent by email to everybody with a Cal Poly email address.

Table 1 summarizes the dates and response rates for each of the three surveys.

Table 1. Survey Dates and Response Rates

\begin{tabular}{lllccc}
\hline $\begin{array}{l}\text { Survey } \\
\text { year }\end{array}$ & Survey administration dates & Reference week & $\begin{array}{l}\text { Total Campus } \\
\text { population }\end{array}$ & $\begin{array}{l}\text { Total Survey } \\
\text { Respondents }\end{array}$ & $\begin{array}{l}\text { Response } \\
\text { Rate }\end{array}$ \\
\hline 2015 & June 9-June 15 & NA & 22,898 & 4,272 & $19 \%$ \\
2018 & May 29-June 8 & May 20-May 26 & 25,170 & 2,625 & $10 \%$ \\
2019 & January 22-February 1 & Most recent 7 days & 24,969 & 2,809 & $11 \%$ \\
\hline
\end{tabular}

The three surveys included overlapping but distinct sets of questions. All three surveys asked respondents to indicate the usual transportation mode they use to commute to and from campus by selecting among several options from a list. The wordings of this question for each survey year, and the corresponding response options, are given below.

- 2015: Thinking about your commute as a whole, how did you usually travel during the spring of 2015. Just so you know, we call this your 'primary mode.'
- Bicycle
- Drive alone
- Drive or Ride with Others (Carpool / Vanpool)
- Public transit (Bus)
○ Walk
○ Other

- 2018: What means of transportation do you usually use to travel to or from campus? If you usually use more than one mode on your commute, select the one you use for most of the distance.

○ Walk

- Bicycle (including electric bicycle)

○ Skateboard

- Motorcycle or scooter

- Drive alone

- Drive or ride with others (carpool or vanpool)

- Get a ride (someone drops you off and continues to another location)

○ Bus 


\section{$\circ$ A ride-hailing service (such as Uber or Lyft) \\ - Other}

- 2019: How do you most frequently travel to and from campus?

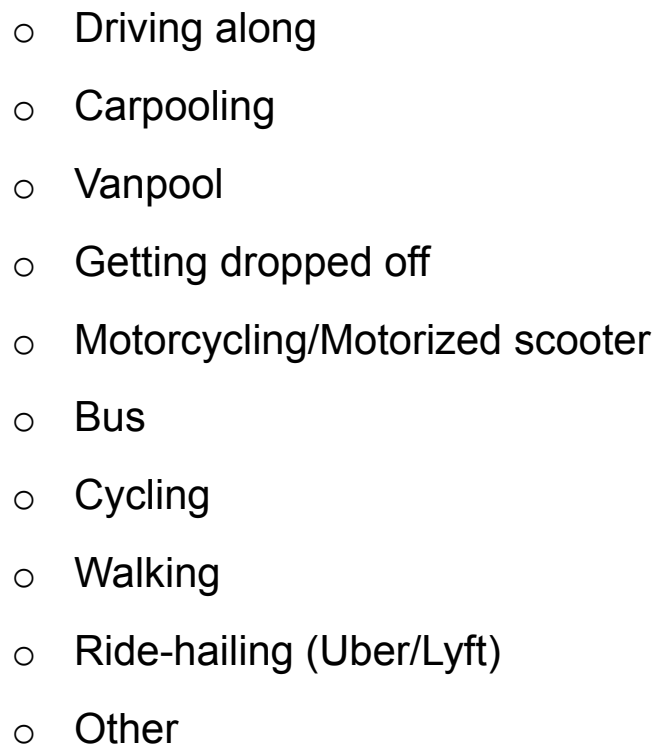

All three surveys also asked respondents to indicate the closest cross streets to their home to enable analysts to calculate respondents' commute distance to campus. The use of cross streets is specific enough to indicate the distance a survey respondent lives from campus, but unlike a full address, protects survey respondents' anonymity. The wording of this question for 2015 is given below:

Please provide us with your local address, so we understand how far you live from campus. Enter the closest intersection, the city, and zip code. Keep in mind that if your permanent address is not the same as your local address, that you should provide your local address.

Enter the closest intersection to your home. Please include both streets that cross. For example: Johnson \& Laurel, California and Monterey, Foothill \& Chorrow, etc.

City

Zip

Many students provided addresses that were out of state or more than 200 miles away from San Luis Obispo, and some students with these very distant addresses indicated that they commuted to campus more four or five times per week. Anecdotally, we know that some students do indeed have long commutes to campus (perhaps as far as 30 miles), but the large number of very distant home addresses suggests that, in spite of the clarifying text asking respondents to indicate their local address rather than their permanent address, many students provided their permanent mailing addresses rather than the loca- 
tions from which they typically commute. Because of this irregularity in the data, we did not include commute distances from the 2015 survey in our analysis.

The issue of very long commute distances that students seemed to report in 2015 did not arise in the 2018 and 2019 surveys. In the 2018 survey, after indicating whether they live on campus, off campus in San Luis Obispo, or outside of San Luis Obispo, the survey asked respondents who indicated they lived off campus the following question:

Please answer for where you live locally when you are traveling to campus on a regular basis. This information will be kept confidential and is used for calculating your approximate distance to campus and to help plan facility needs around campus.

What intersection is nearest to your home? Please include both streets that cross.

Street 1:

Street 2:

Respondents who had indicated that they lived outside of San Luis Obispo were also asked to provide the name of their city and zip code.

In 2019, the survey prompted respondents to select their commute distance from a list of possible ranges, followed by the following optional question:

OPTIONAL, Where do you live? (Please indicate both cross streets for the nearest intersection)

Cross Street 1

Cross Street 2

City

\section{Zip code}

For the 2018 and 2019 surveys, we calculated the commute distance for each respondent by calculating the driving distance from the provided cross streets to the main Cal Poly campus using the Google Maps Application Programming Interface (API), via the googleway package in $\mathrm{R}^{9}$

The 2018 and 2019 surveys also prompted respondents to answer questions about their travel during the prior week (regardless of whether the respondent considered the prior week to be typical). The reference week for the 2018 survey was the week of Sunday, May 20-Saturday, May 26. Respondents to the 2019 survey answered questions about the seven days immediately preceding the day they took the survey. Since the survey ran from January 22 until February 1, the reference week included dates as early as January 15 and as late as January 31. 
Both the 2018 survey and the 2019 survey also asked respondents to indicate the number of round trips they made to and from campus on each day of the reference week. The 2018 survey asked respondents to indicate how many total round trips they made on each day, then asked them to indicate which of nine modes they used on each day. The format of this question made it impossible to estimate survey day mode shares for respondents who used multiple modes on the survey day (without making an arbitrary assumption about how the survey-day trips were distributed across modes). The 2019 survey corrected for weakness by combining these two questions and asking respondents to indicate how many trips they made to and from campus by each of nine modes during the reference week.

For the 2019 survey, we calculated the vehicle miles traveled (VMT) for each campus community member by summing the number of estimated round-trips they made by each automotive mode. To estimate an individual's VMT components for driving alone and for riding a motorcycle, we multiplied (a) the number of trips made by those modes over the course of the week by (b) the estimated trip distance, and then (c) doubled the product to account for round trips.

For the 2019 survey data, we adjusted the VMT estimation for automotive modes with multiple passengers, including carpooling, being dropped off, and taking the bus, by making the same calculation as before, but then dividing by the number of passengers survey respondents indicated were in their vehicle. This correction factor helps to apportion the appropriate fraction of the VMT components for these modes among passengers, so as to avoid double counting trips and thereby over-estimating total VMT when summing VMT across the entire campus community.

We could not apply this correction factor to the 2018 survey data, because the 2018 survey did not indicate how many trips respondents made by each mode (a problem which the 2019 survey corrected for). Instead, it indicated the total number of trips on each day, and whether the respondent used each of nine modes, as a yes-or-no question. To generate VMT estimates from this data, a correction factor was generated based on 2019 data as follows: first, a low VMT value was calculated from both the 2018 and 2019 surveys corresponding to what each respondent's VMT would have been if he or she had used each indicated motorized mode for only one survey-day trip; next, a correction factor was calculated from 2019 data as the ratio of this low VMT value to the actual VMT value; and finally, we estimated the 2018 VMT value by multiplying the 2019 correction factor by the 2018 low VMT value.

\section{Weighting}

Although only a sample of the overall campus population participated in the survey, the goal of our analysis was to estimate population-level statistics. Two facts complicate this effort. Firstly, different groups (e.g., gender, undergraduate vs graduate) responded at different rates. Secondly, different groups were found to use the different travel modes at different rates. Therefore, it would be inappropriate to simply scale up the sample to the population at the same rate for all individuals. We consequently develop and assign different "weights" for each respondent, based on their group membership, with higher weights for individuals in groups with lower response rates and lower weights for those 
with higher response rates. For the purposes of this research, it was implicitly assumed that respondents are representative of the rest of the population within their group.

In the surveys, respondents were assigned to one of four role groups: undergraduate students; graduate students; faculty; and staff. We weight all statistics presented in this report to adjust the sample to resemble the population proportion of those role groups. More specifically, each individual in a given role group was assigned a weighting factor so that the group's weighted representation in the sample is the same as their proportion in the overall campus population.

As is common in surveys, the samples were disproportionately comprised of women. ${ }^{10}$ In addition to weighting individuals by their role group, these differences in response rates among men and women, in each role group, were corrected so that the weighted representations of men and women in the sample were equal to the proportions of men and women in each role group in the overall population.

In the figures given below, 95-percent confidence intervals are shown based on standard errors that incorporate survey weights. The weighted survey responses are assumed to have the characteristics of a random sample.

\section{USUAL COMMUTE MODE TO CAMPUS}

In all three surveys, respondents were asked to identify the mode they usually" (2015 and 2018) or "most frequently" (2019) use to travel to and from campus. Hereafter, this is referred to as a respondent's "typical" mode. Figure 1 shows the variation in typical mode shares, over all individuals, for commutes to campus, for all survey years. As shown, there was a large reduction over time in the share of commuters walking to campus; between 2015 and 2019, the share of commuters walking to campus was halved, dropping from 34 percent to 17 percent. The increase in the share of commuters driving to campus mirrored this change with an increase of 16 percentage points from 30 percent to 46 percent. 


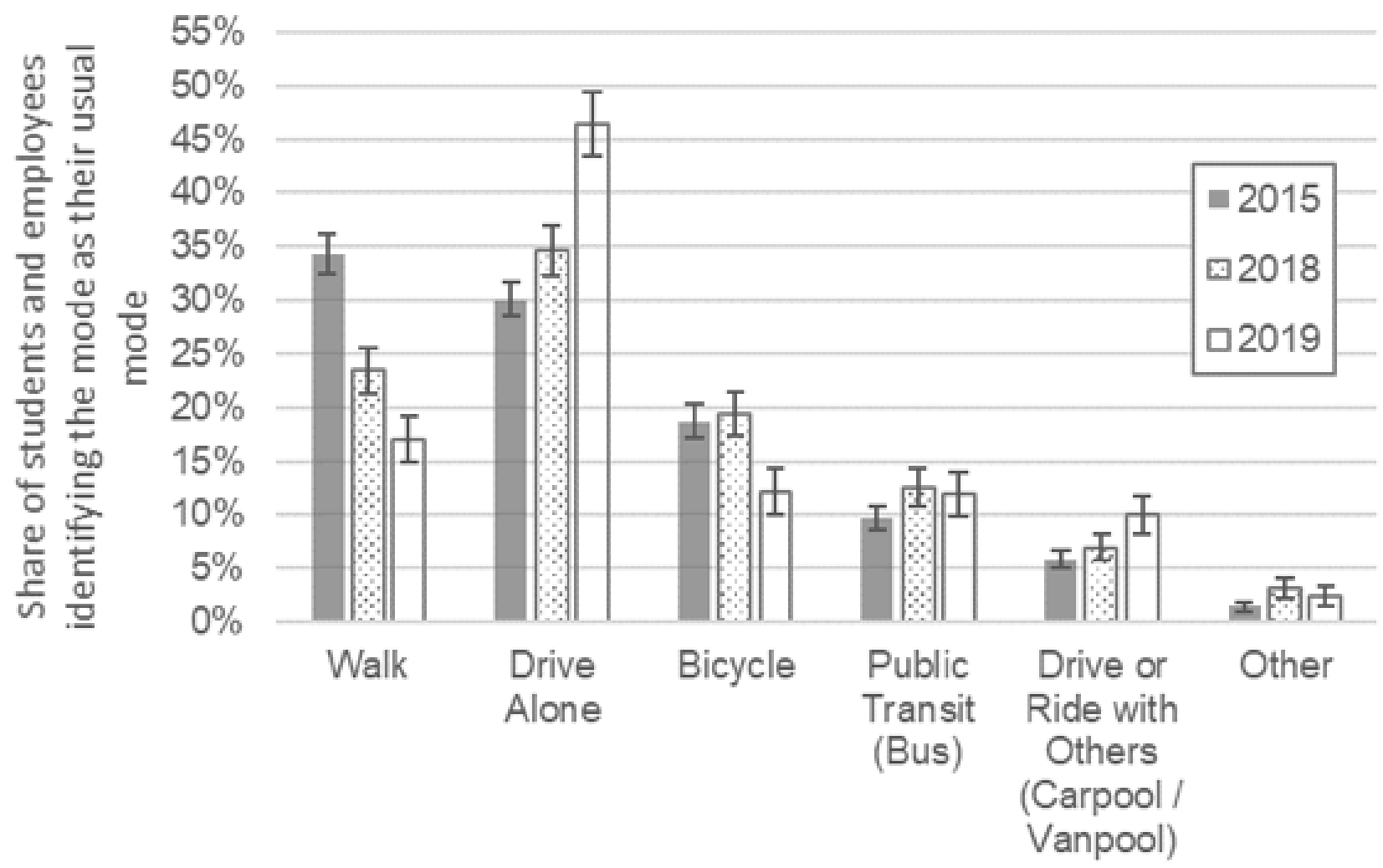

Figure 1. Usual Mode Shares of Student and Employee Trips to and from Campus

Other changes in mode shares include a seven-percentage-point reduction in cycling from 2018-2019, a three percent increase in public transit mode share from 2015-2018, and a three percent increase in carpooling from 2018-2019. The reduction in cycling between 2018 and 2019 might be related to seasonal weather, since the 2018 survey took place in late May, and the 2019 survey took place in late January. However, San Luis Obispo does enjoy a moderate climate year round. The average temperature during the spring 2018 reference week was only 59 degrees Fahrenheit, and the average temperature during the winter 2019 reference week was 55 degrees Fahrenheit, a difference of less than five degrees.

As a university, Cal Poly's campus population turns over at a relatively high rate: every year, a graduating class is replaced with a class of incoming students. In order to properly interpret the changes in mode shares shown in Figure 1, it is necessary to understand whether these changes represent behavioral changes by the same individuals or whether they stem from differences in travel habits between classes of entering students and classes of graduating students. We identified four sub-populations of the overall campus community who appeared in multiple surveys and represented approximately the same populations: the graduating class of 2021 (who would have been first-year students in the 2018 survey and second-year students in the 2019 survey); the graduating classes of 2019 and 2020 (who would have been second- and third-year students in the 2018 survey, and third- and fourth-year students in the 2019 survey-these two classes were lumped together for simplicity); the graduating class of 2018 (who would have been first-year students in the 2015 survey and fourth-year students in the 2018 survey); and employees (while we recognize that there was some employee turnover between 2015 and 2019, we 
assumed this to have been a relatively stable population). While the individuals included in each survey differed from year to year, the samples are taken from the same overall population from each group.

Figure 2 shows the changes in the proportions of each of the cohorts identified above that commuted to campus by driving alone during the reference week. Among employees, the proportion driving alone increased slightly across the three survey years, 95-percent confidence intervals among the three years overlap. For the class of 2018, the proportion driving alone doubled from 18 percent in 2015 (when those students were in their first year) to 36 percent in 2018 (when those students were in their fourth year). Most of these students had graduated by the time the 2019 survey was administered.

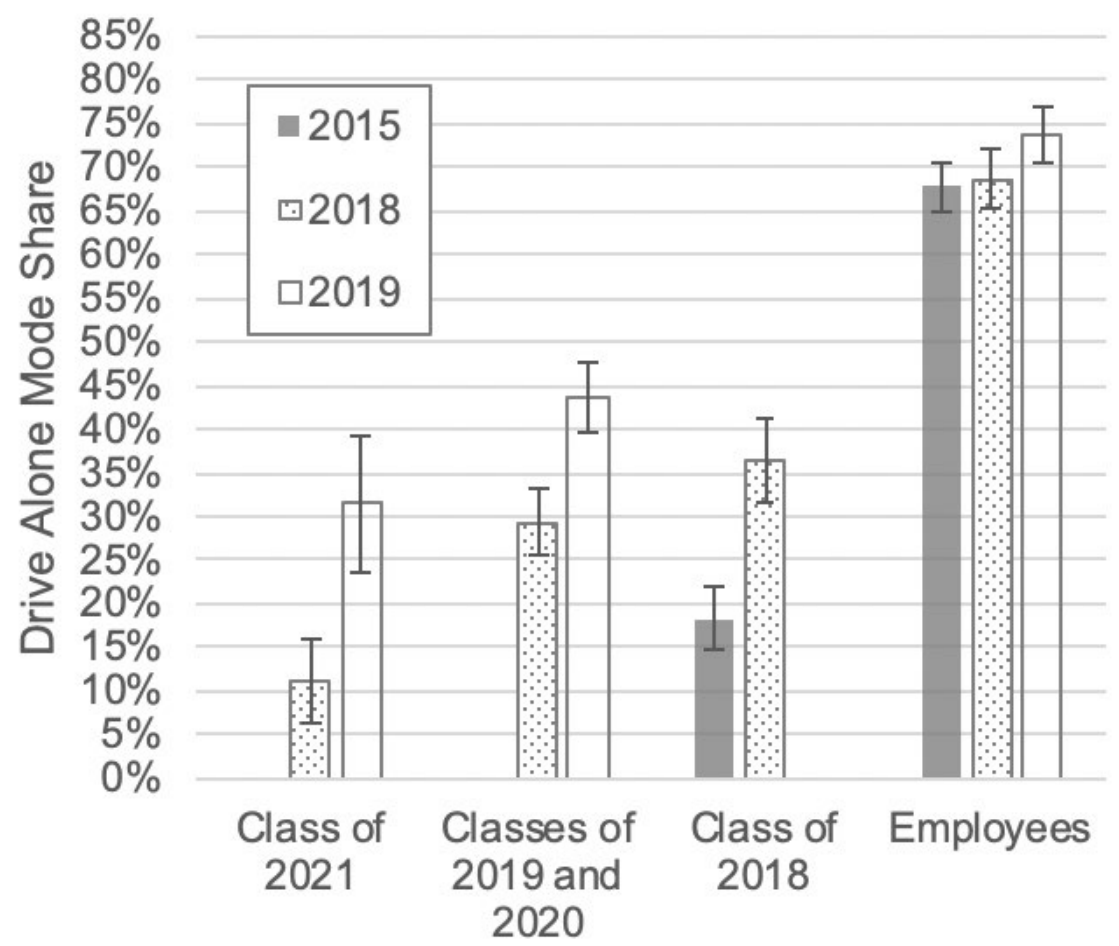

Figure 2. Within-Cohort Changes in Drive Alone Mode Shares, 2015-2019

The classes of 2019,2020 , and 2021 had not yet arrived on campus when the 2015 survey was administered, but for them as well, the proportions driving alone grew from 20182019. The increase was especially pronounced among members of the class of 2021. These students were the first class of first-year students who were not permitted to park on campus, which likely explains the low proportion of students (11 percent) who drove alone to campus during the reference week. In 2019, upon being permitted to park on campus as they entered their second year, the estimated proportion of this cohort driving alone to campus nearly tripled, increasing from 11 percent to 31 percent. Over that same period, the proportion of the students in the classes of 2019 and 2020, who were secondand third-year students in 2018 and third- and fourth-year students in 2019, driving alone increased by a factor of about 1.5, from 29 percent in 2018 to 44 percent in 2019.

Each cohort of students shown in Figure 2 increased their car-dependence over time. 
However, this age effect alone is not enough to explain the increases in driving mode shares observed in Figure 1, suggesting that different cohorts also had different driving habits from each other. If all cohorts had the same proportion driving along in first year, and all cohorts had the same proportion driving alone by fourth year, then the overall proportion of all students driving alone to campus would be relatively consistent over time, which Figure 1 shows to be false.

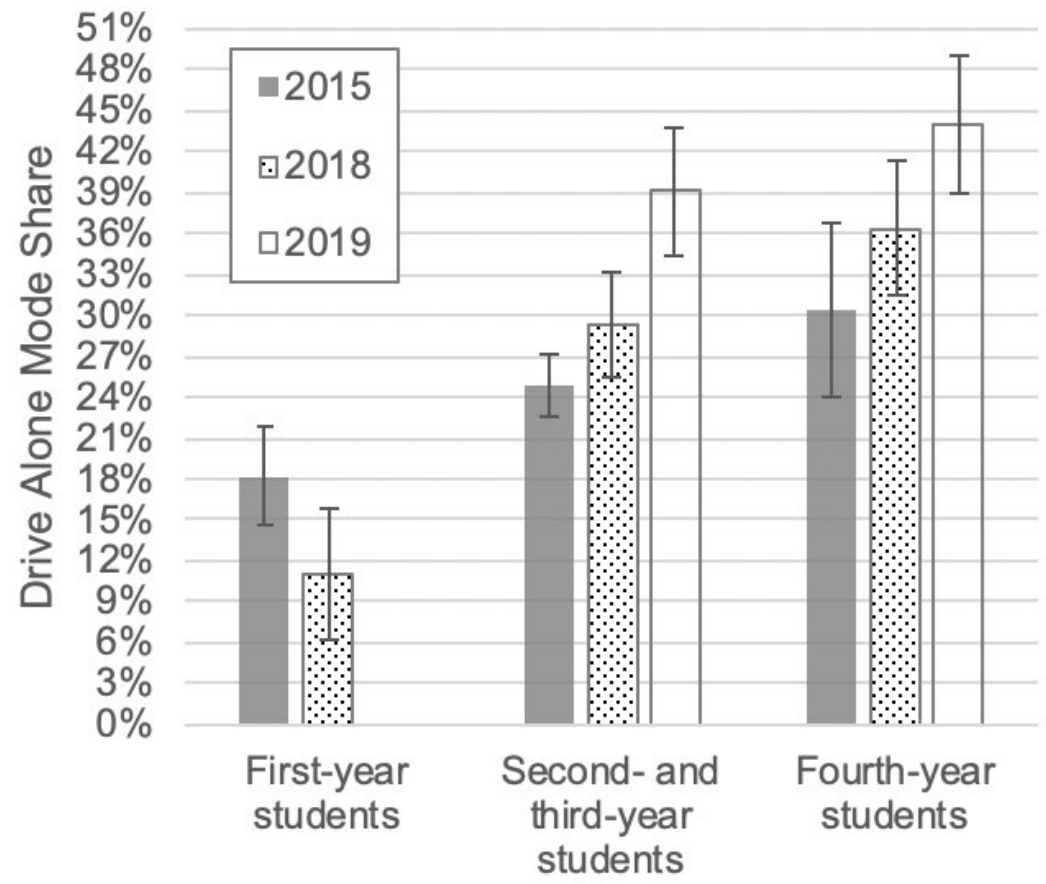

Figure 3. Between-Cohort Differences in Drive Alone Mode Shares, 2015-2019

Note that Figure 2 shows within-cohort changes over time, and that groups of bars represent the same population, with shading to indicate the driving mode shares in each of three different years. In contrast, Figure 3 shows between-cohort changes over time, so that groups of bars represent two (for first-year students) or three (for all other students) separate (or in the case of second- and third-year students, overlapping) populations. Figure 3 shows differences in the proportion driving alone for students at three different ages in three different survey years. In all three survey years, the proportion driving alone was the highest among fourth-year students. Moreover, it is also the case that fourth-year students in later years had higher proportions driving alone than fourth-year students in earlier years. Over the time period covered by the three surveys, the proportion of fourthyear students driving alone to campus increased by a factor of nearly 1.5 , from 30 percent in 2015 to 44 percent in 2019. Increases over time in the proportions driving alone of the second and third year age-classes were equally dramatic, increasing from 25 percent in 2015 to 39 percent in 2019. The 2019 survey did not ask first-year students about their usual commute mode to campus. The share of first-year students driving alone to campus decreased from 2015 to 2018, but the 95-percent confidence intervals for the proportions in each year overlap (the relatively low response rate from first-year students resulted in a wide confidence interval). As shown in Figure 2, the reduction in driving alone by firstyear students from 2015 to 2018, following the introduction of the prohibition on first-years' parking on campus, did not persist when those students entered their second year, with 
the later class of second years in fact driving alone at higher rates.

As students shifted towards increased rates of driving alone, the question arises as to which modes were they shifting away from. Figure 1 shows that the population increases in the overall proportion driving alone were mirrored by approximately equal decreases in the overall proportion walking. Figure 4 parallels Figure 2 in showing the mode walking mode shares within four sub-populations (three groups of students, plus employees) changed over time, where each set of bars represents the same population individuals from which the survey sampled. The share of employees walking to campus was consistently low (less than 2 percent) across all survey years. The most dramatic change over time in the proportion walking was among the class of 2018. Sixty percent of the class of 2018 typically walked to campus during their first year; by their fourth year, this figure had fallen to 18 percent. Between 2018 and 2019, the proportion walking of the classes of 2019 and 2020 also decreased, from 27 percent to 16 percent. Likewise, the proportion walking of the class of 2021 decreased from 2018 to 2019, but the 95-percent confidence intervals for those proportions overlap.

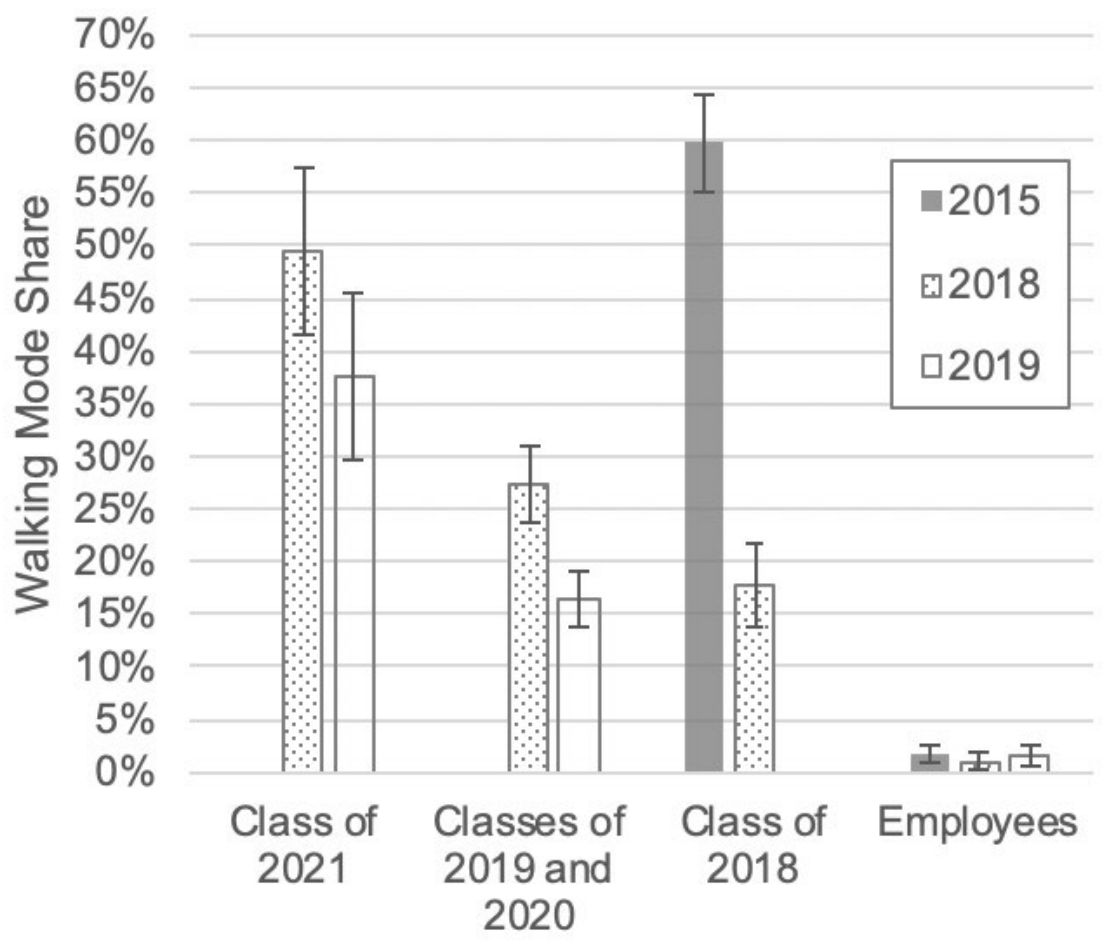

Figure 4. Within-Cohort Changes in Walking Mode Shares, 2015-2019 


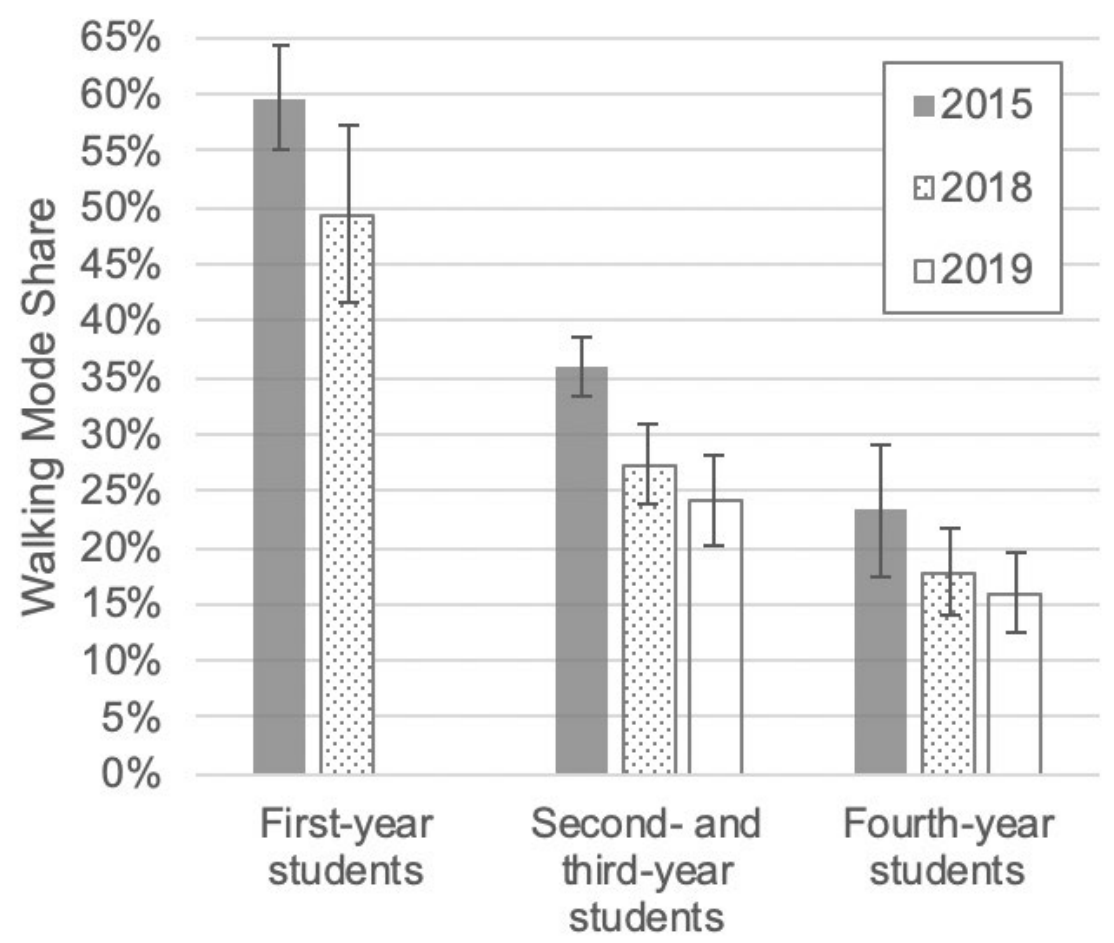

Figure 5. Between-cohort differences in walking mode shares, 2015-2019

As Figure 4 shows, some of the reductions in walking shown in Figure 1 are age effects: particular populations have lower proportions of people walking to campus as the members of that population get older. Figure 5 shows that cohort effects were less substantial. Students in each successive class of students were less likely to walk to campus than students in the previous class, but for the most part, the confidence intervals for walking mode shares overlapped between successive classes. The only exception to this was for the decrease from 36 percent of second- and third-year students walking to campus in 2015 to 24 percent of second- and third-year students walking in 2019.

As Figure 1 shows, bicycling mode shares for the overall campus community were relatively consistent between 2015 and 2018, followed by a decrease of about seven percentage points from 19 percent in 2018 to 12 percent in 2019. Figure 6 and Figure 7 show the breakdown of these changes into the changes for employees and for the three undergraduate cohorts. Figure 6 shows changes over time in the proportions bicycling within each cohort, and indicates that the class of 2018 underwent a substantial increase in cycling between 2015 (when they were first-year students) and 2018 (when they were fourth-year students). In contrast, for the classes of 2019 and 2020, the proportion cycling decreased between 2018 (when they were second- and third-year students) and 2019 (when they were third- and fourth-year students). 


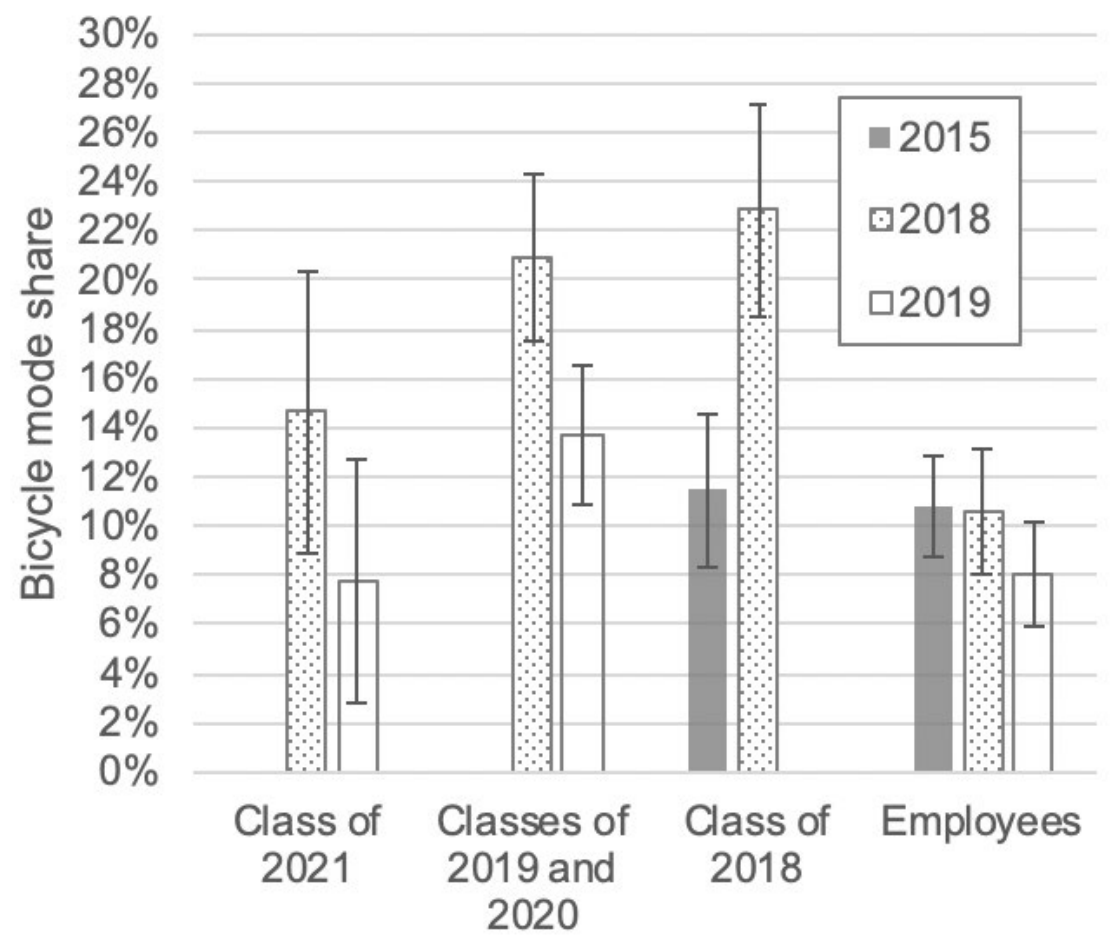

Figure 6. Within-Cohort Changes in Bicycle Mode Shares, 2015-2019

Figure 7 shows the differences in bicycling mode shares between successive cohorts, for three different years, and indicates that the there was a substantial decrease in the proportion of second- and third-year students commuting to campus by bicycle between 2018 and 2019. There was also a decrease over time in the proportion of fourth-year students cycling.

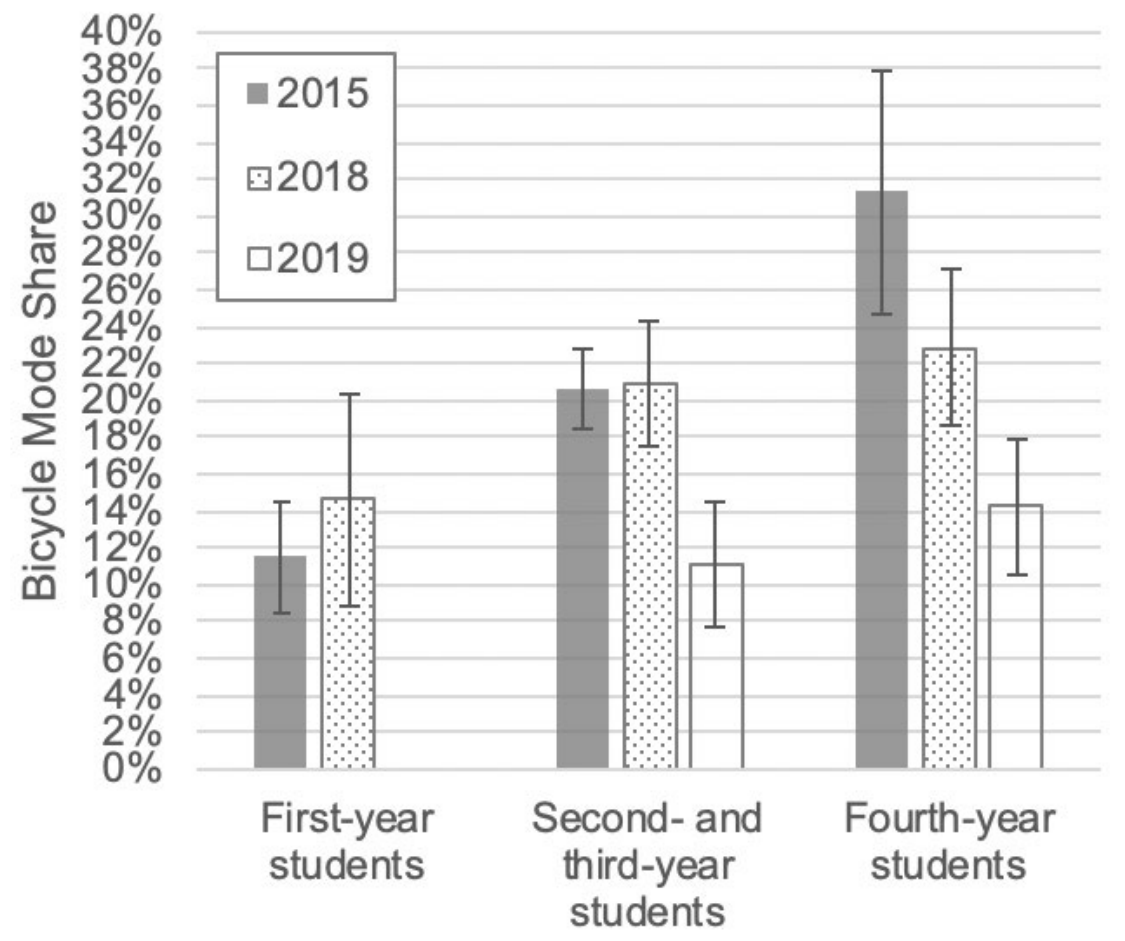

Figure 7. Between-Cohort Differences in Bicycle Mode Shares, 2015-2019 
As Figure 8 and Figure 9 show, in 2015 the share of first-year students (class of 2018) commuting to campus by transit was especially low. In the 2018 survey, when those students were in their fourth year, their proportion commuting by transit had increased to be more similar to those of other cohorts (Figure 8). Subsequent classes of first-year students had transit mode shares that were more similar to those of other students (Figure 9).

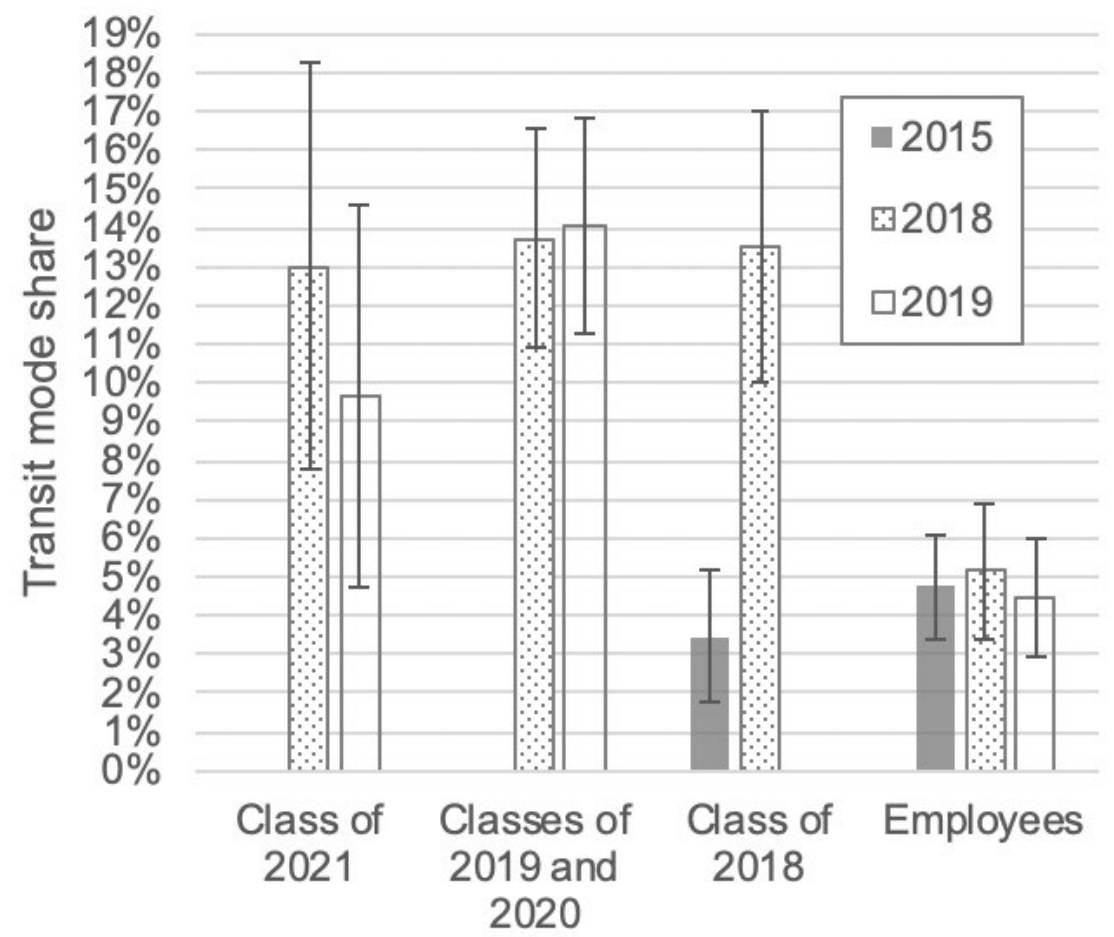

Figure 8. Within-Cohort Changes in Transit Mode Shares, 2015-2019

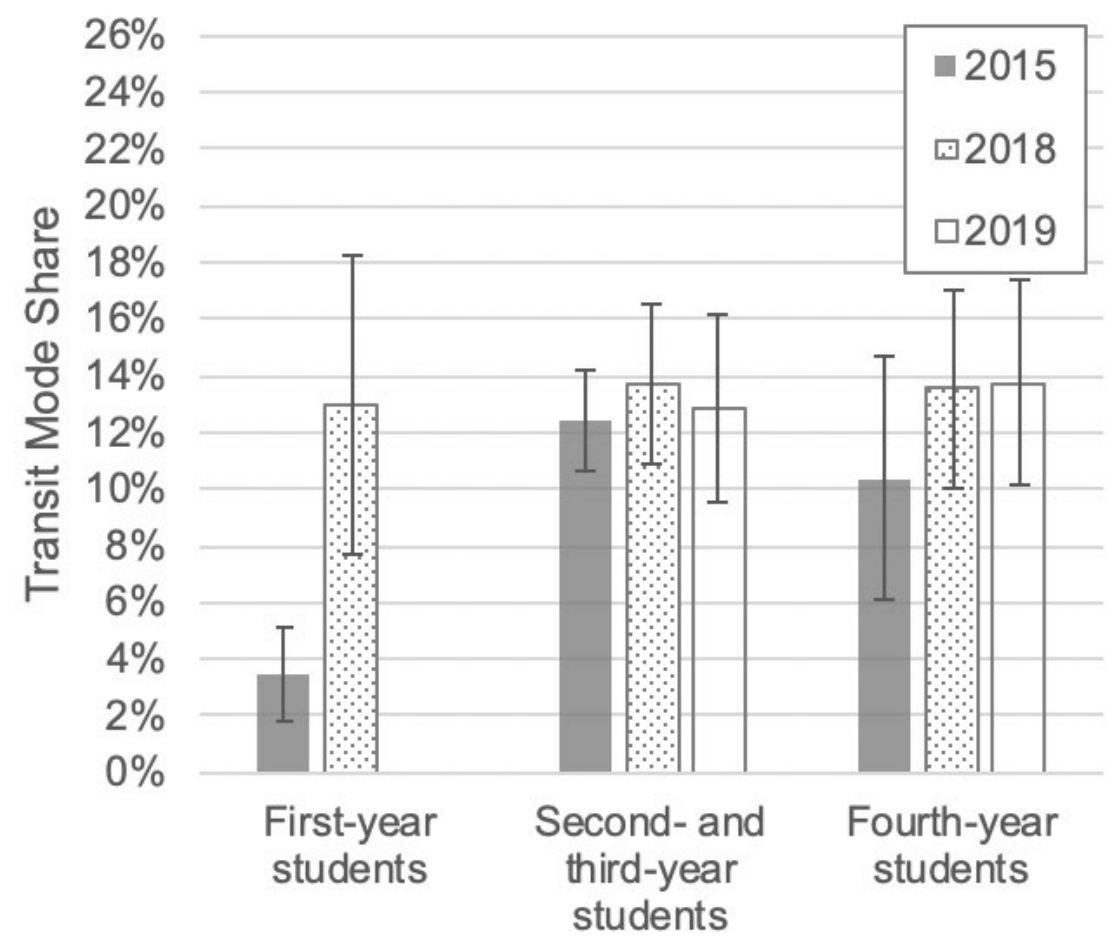

Figure 9. Between-Cohort Differences in Transit Mode Shares, 2015-2019 
Figure 10 shows that the share of employees carpooling to campus decreased by about four percentage points from 13 percent to 9 percent between 2015 and 2019. For each of the student cohorts, the 95-percent confidence intervals for the proportions of students commuting by carpool in each year overlapped with those for other years. However, as shown in Figure 11, the entire 95-percent confidence interval for the proportion of fourthyear students carpooling in 2019 is greater than the entire 95-percent confidence interval fourth-year students carpooling in 2015.

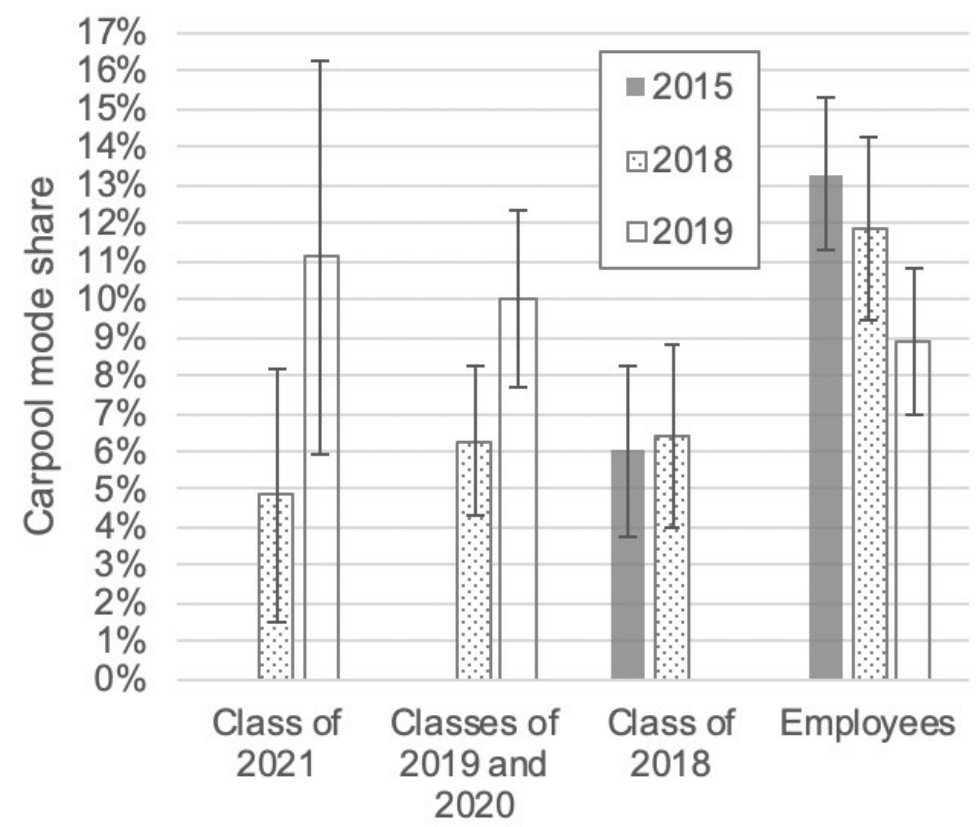

Figure 10. Within-Cohort Changes in Carpool Mode Shares, 2015-2019

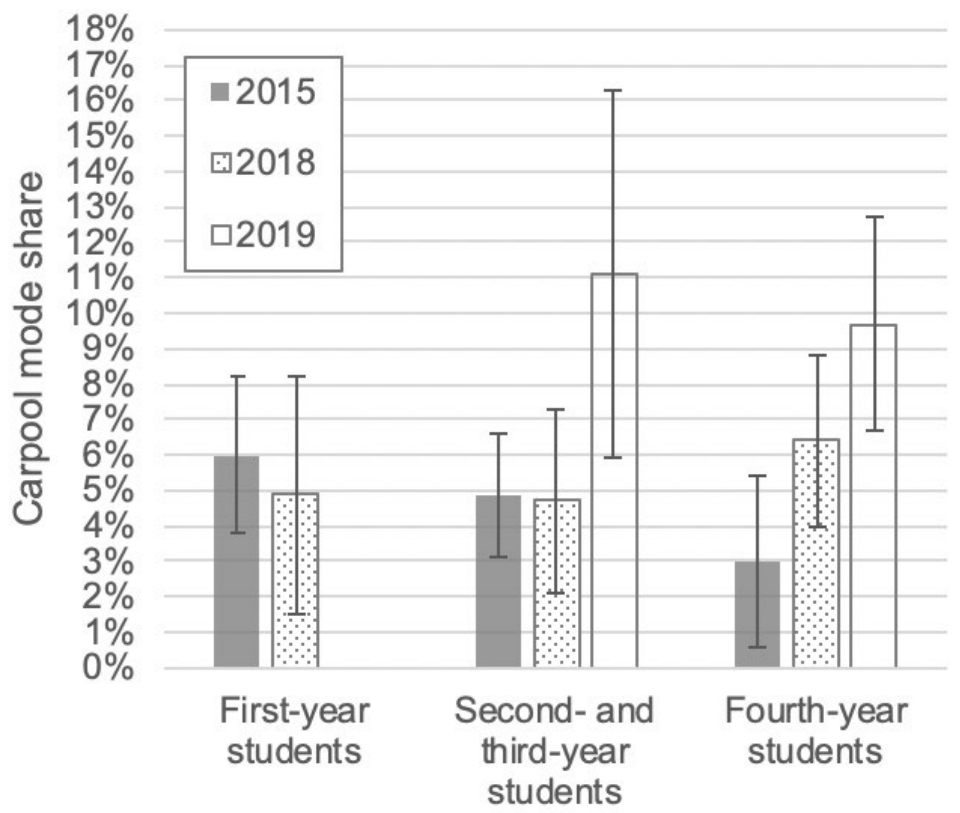

Figure 11. Between-Cohort Differences in Transit Mode Shares, 2015-2019 


\section{COMMUTE DISTANCE}

Some of the increased reliance on driving over time described in the previous section might be explained by increasing distances between campus and the homes of Cal Poly students and employees. Figure 12 shows that the average commute distance to campus of members of the Cal Poly community increased from 5.3 miles in 2018 to 6.4 miles in 2019 , which likely means that fewer students and employees lived within walking distance of campus at the time of the 2019 survey than at the time of the 2018 survey.

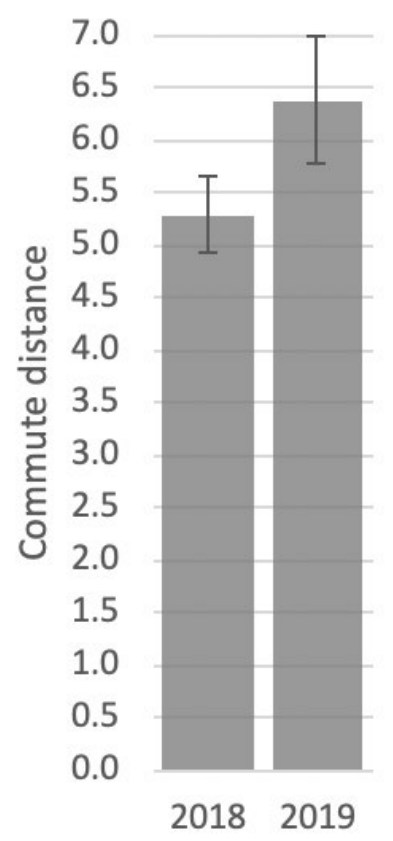

Figure 12. Change in Average Commute Distance for Students and Employees, 2018-2019

Figure 13 shows that, while the average commute distance of Cal Poly employees may have increased slightly between 2018 and 2019, the 95-percent confidence intervals for the average commute distances in those two year overlap. Likewise, students in the class of 2021 had about the same commute distances to campus as second-year students that they did as first-year students. Members of the classes of 2019 and 2020 seem to have moved further away from campus between the 2018 and 2019 surveys; their commute distances increased from about 3.7 miles to about 5.1 miles. 


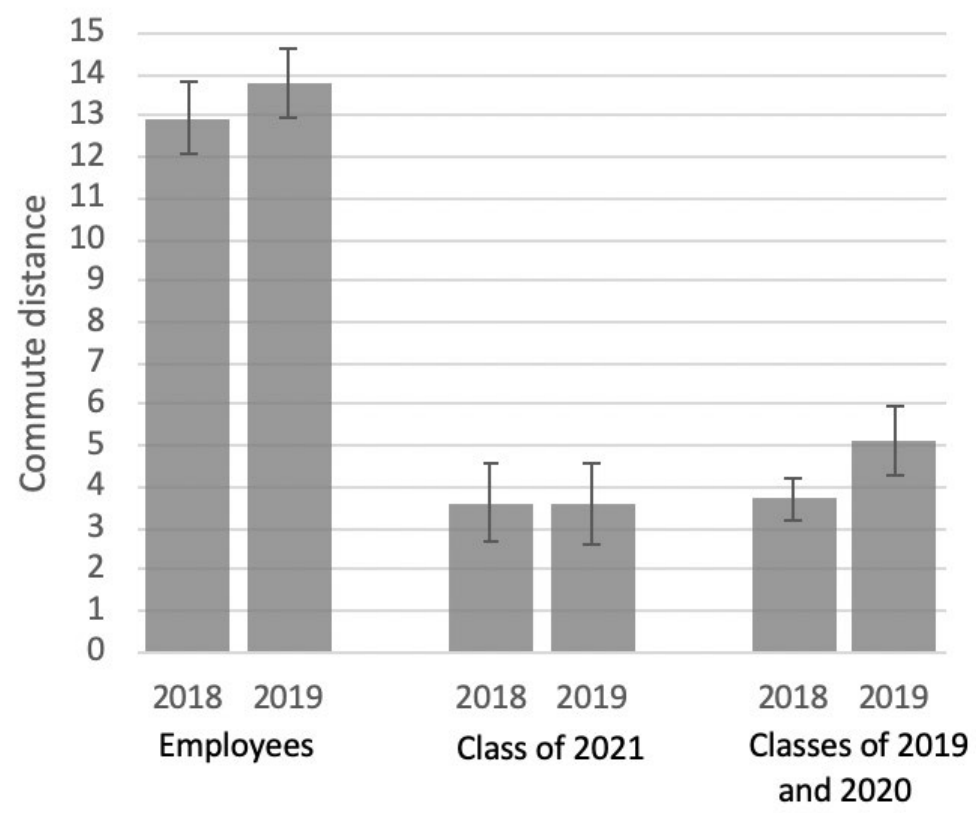

Figure 13. Within-Cohort Changes in Average Commute Distance, 2018-2019

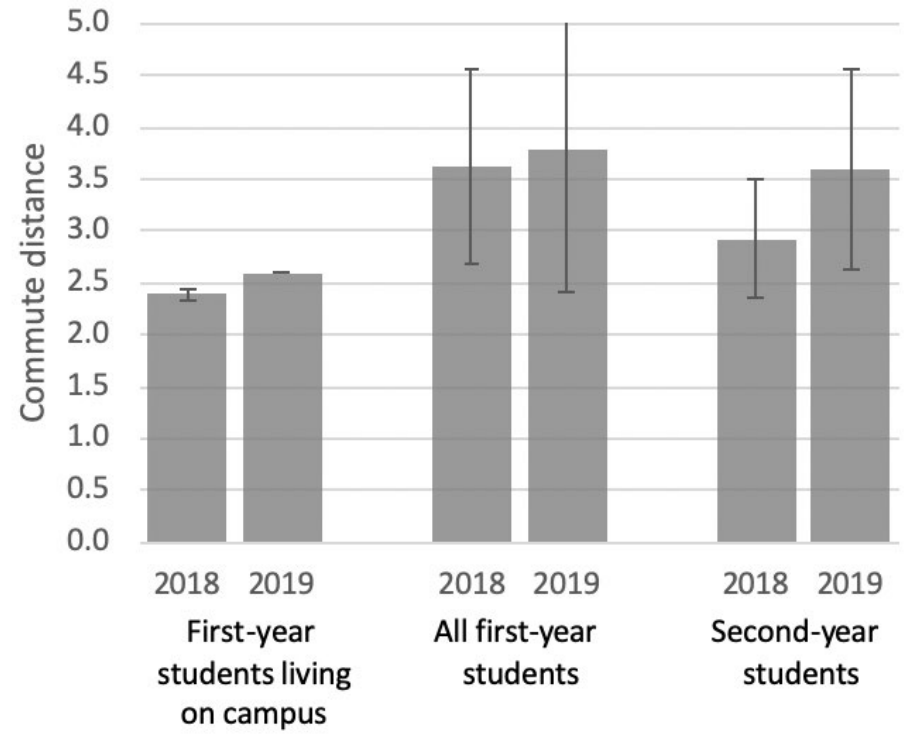

Figure 14. Between-Cohort Differences in Average Commute Distance, 2018-2019

Figure 14 shows that there were not substantial increases in commute distances to campus between successive classes of first- and second-year students from 2018 to 2019.

\section{CAMPUS TRIP GENERATION}

Figure 15 shows that the number of weekly round trips that members of the Cal Poly community made to campus increased between 2018 and 2019, but that the 95-percent confidence intervals for the two years overlap. Figure 16 shows that students in the classes of 2019 and 2020, and in the class of 2021 increased their number of weekly trips to campus between 2018 and 2019. 


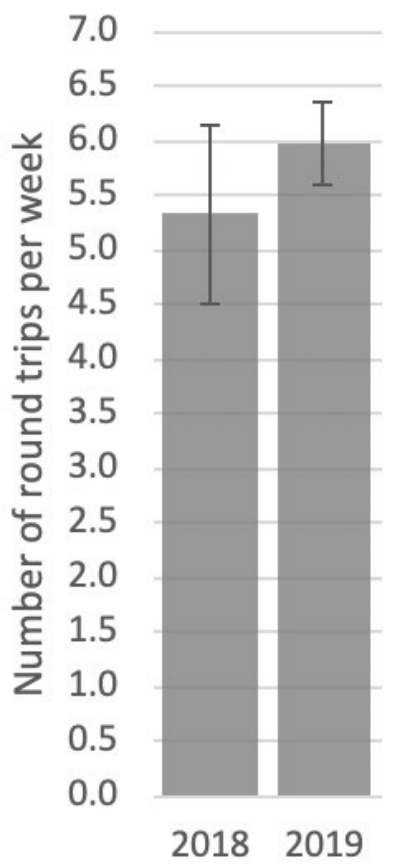

Figure 15. Change in Weekly Round Trips to Campus for Students and Employees, 2018-2019

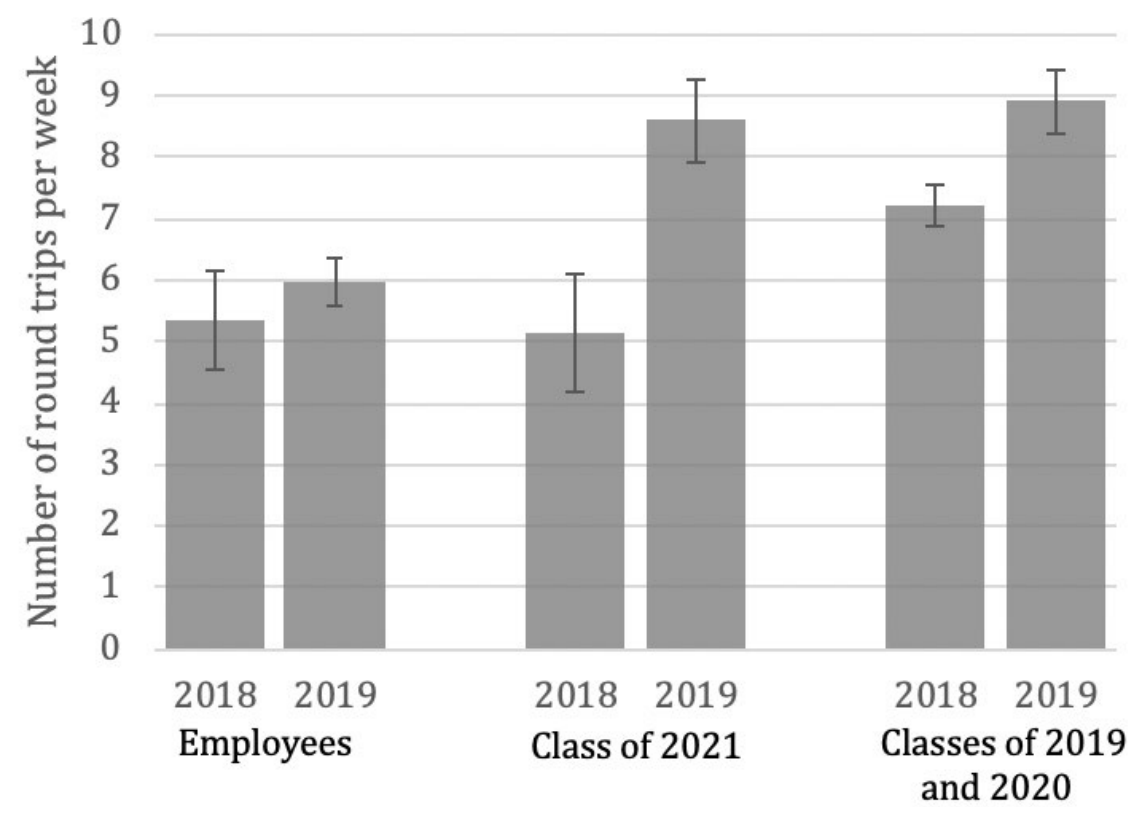

Figure 16. Within-Cohort Changes in Weekly Round Trips to Campus, 2018-2019 


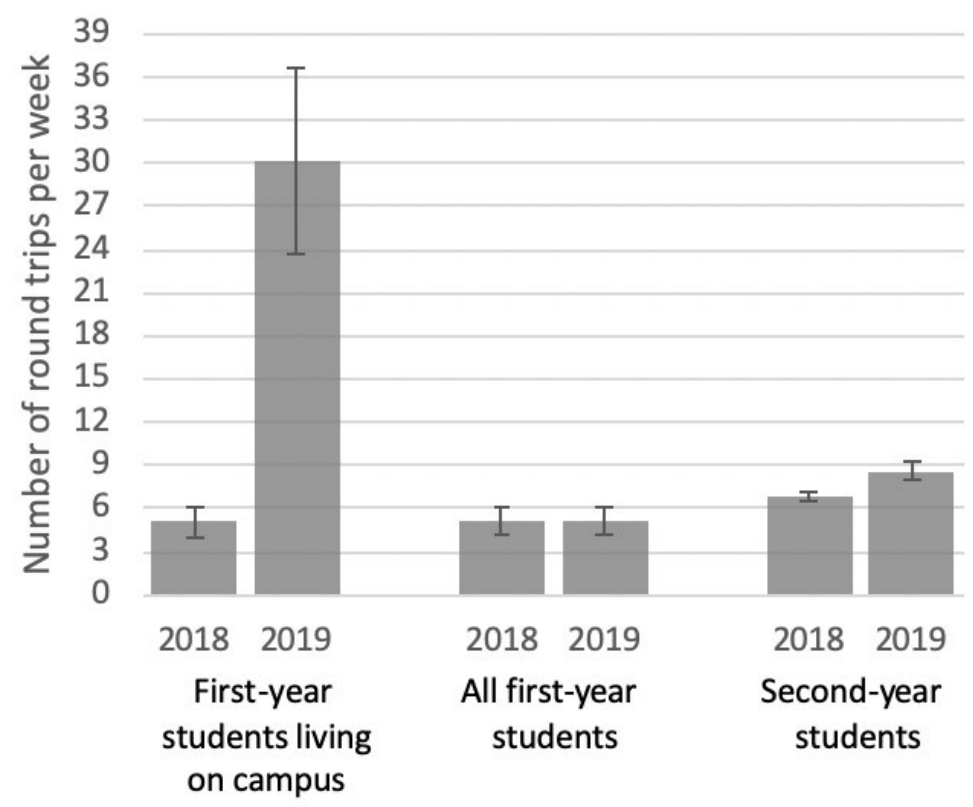

Figure 17. Between-Cohort Differences in Weekly Round Trips to Campus, 20182019

Figure 17 shows a five-fold increase in the number of trips to and from campus by first-year students, from 2018 to 2019 . This is likely because of differences in the way the question was phrased in the two surveys, such that students in 2018 would have interpreted the question as referring to the number of trips from their on-campus residences to off-campus locations, and students in 2019 interpreted the question as referring to the number of trips from their on-campus residences to other on-campus locations. At Cal Poly, first-year students are required to live on campus, and continuing students are not.

\section{COMMUTE-GENERATED VEHICLE MILES TRAVELED}

Changes in campus-generated VMT can arise from a combination of three behavioral changes by members of the campus community: changes in the commute distance to campus; changes in the frequency of trips to campus; and changes in the share of trips to campus that take place by car (transit trips were not assumed to influence campus-generated VMT, since transit routes and schedules are determined by the city-operated transit agency). As described in the preceding two sections, while the frequency of travel to campus by members of the campus community did not increase between 2018 and 2019, the average commute distance did increase by about one mile, and the share of commute trips taking place by single-occupancy vehicles increased from 35 percent to 46 percent. Combined, these changes resulted in a 30 percent increase in average weekly VMT per person, from 50 miles per person per week in 2018 to 65 miles per person per week in 2019.

\section{CONCLUSION}

This chapter began by listing four potential explanations for the increase in campusgenerated VMT observed in Figure 1: 
1. Immediate effects of the introduction of a 2018 campus parking policy change that prohibited first-year students living on campus from parking on campus.

2. Lasting effects of the above policy that persist as the first-year students who had been prohibited from parking on campus enter their second year.

3. Changes in the habits of the individuals commuting to and from campus (unrelated to changes in parking policy).

4. Replacement of graduating students with incoming students with different habits (unrelated to changes in parking policy).

This chapter then investigated the relative roles of these potential explanations.

Student cohorts were observed to become more car-dependent and to live further from campus as they age from their first year to their fourth year (as shown in Figures 2, 4, 6, 8,10 , and 12). This effect would not necessarily result in increases in overall increases in driving over time, since the oldest, most car-dependent group (fourth-year students) graduates each year and is replaced by a less car-dependent group (first-year students). However, the results of successive surveys also suggest that younger cohorts of students (e.g. the class of 2021 relative to the class of 2020) are increasingly car-dependent (as shown in Figures 3, 5, 7, 9, and 11). For example, second-year students in 2019 had about the same commute distances as the previous year's second-year students, but were more than 30 percent more likely to drive alone to campus.

The restriction on on-campus parking for first-year students was followed by, and presumably caused, a reduction in the proportion of first-year students driving alone to and from campus. Based on studies that suggest that experience with alternatives to driving alone makes people less car-dependent later in life, it was expected that this reduction in driving might persist into these students' second year, even once the restriction on oncampus parking was lifted. ${ }^{11}$ If this was the case, we would expect students who were firstyears in 2018 to be less likely to drive to campus during their second year than previous classes of second-year students had been. However, the opposite appears to have occurred. Second- and third-year students in 2019 were even more likely than their 2018 counterparts to drive alone to campus. 


\section{COMPARISON OF ALTERNATIVE TRAVEL DATA SOURCES}

\section{BACKGROUND}

VMT estimation has always been a challenging problem, with a variety of models being used in a variety of contexts. ${ }^{12}$ The challenge is even more acute in "special generators" such as college and university campuses, which have users with unique travel patterns, compared to other land uses and facilities. ${ }^{13}$ Although the exact criteria for what constitutes a special generator can vary, in general, the term tends to describe any facility or land use whose traffic demands do not follow a typical, AM/PM peak trip generation pattern. Examples of special generators include colleges and universities, hospitals, sporting and event arenas, and military bases. ${ }^{14} \mathrm{~A}$ special challenge for college and university trip generation models relates to the fact that these facilities typically also contain a variety of traditional land uses within the campus limits (e.g., residential, commercial, recreational, office, etc.), constantly have people entering and leaving campus, and may even have other special generators within their limits (e.g. associated research hospitals). The challenge that this presents to regional TDM measures and metropolitan planning organizations (MPOs) has been noted by Garikapati et al. ${ }^{15}$

In order to quantitatively model the specific trip generation patterns typical of universities, travel surveys have proven to be a useful tool, since they allow for a rich data set, with a variety of individual-level data on traveler characteristics known to influence travel behavior. In many cases, there is no other way to collect this data. Specific applications of the survey data include simple assessments of whether different student populations have different travel patterns and more thorough travel demand models constructed using survey data (e.g., Maricopa Association of Governments). ${ }^{16}$

Travel surveys are also used to understand the nature of the impact of the transportation system on the environment. Many universities, including Cal Poly, are creating "Climate Action Plans," with strategies to reduce campus VMT, informed by travel surveys. ${ }^{17} \mathrm{~A}$ few universities regularly conduct annual travel surveys; for example, the University of California, Davis conducts annual travel surveys to understand its campus travel demand and behaviors (up-to-date data on the most survey is available publicly at https://its. ucdavis.edu/campus-travel-surveys/).

While travel surveys are applied widely, the weaknesses of this approach have been welldocumented, including biases and resulting errors. ${ }^{18}$ There are a number of publications that offer solutions and case studies of how to best manage these issues. ${ }^{19}$ One of the biggest issues with most travel behavior surveys is the problem of low response rates; statistically, this means that any analysis performed on the data has limited precision and accuracy. Lower-response rates among certain demographics of the campus community also present a challenge.

With such uncertainty presented by the use of survey data alone, it can be helpful to seek additional data sources to augment the findings from the survey data. Transportation planning and engineering consultancy group Fehr \& Peers conducted a 2017 VMT analysis for the Stanford University campus that utilized cordon counts and survey 
data, in conjunction with the Santa Clara Valley Transportation Authority regional travel demand model, in order to estimate the annual VMT for the Stanford campus. ${ }^{20}$ Among the novel techniques they used to augment the survey information, one of the more exciting is the use of mobile device data for estimating travel demand. It is well beyond the capabilities of the average transportation practitioner to process raw mobile device data and use sophisticated analyses to identify, categorize, and clean singular "trips"; accordingly, a number of companies provide services which analyze and package mobile device data from third-party vendors for use in practice. Within the transportation data industry, these vendors include AirSage, CitiLogik, and StreetLight Data (SLD). SLD, the vendor which provided data for this study, is a subscription-based web platform. It allows users to define their own boundaries and analysis parameters, even including a web mapping interface for direct creation of traffic analysis zones (TAZs). These user capabilities distinguish it from other similar vendors.

Turner, of the Minnesota Department of Transportation, compared the mobile device data on traffic volumes to data collected by both permanent (69 locations) and temporary $\left(8,700\right.$ locations) traffic counting devices. ${ }^{21}$ The most relevant finding for this research was that mobile device data tends to overestimate vehicle counts. Additionally, it was found that estimates were more accurate for locations with higher annual average daily traffic (AADT). It is also worth mentioning that the study was originally intended to also include data from other providers, but two other companies (which are not named) decided not to participate in this study. There has also been some research about the potential accuracy and privacy issues of the mobile device data sources. Johnson and Smith considered the broader implications of trying to replacing traditional surveys with big data applications. ${ }^{22}$ Johnson and Smith noted the issue of transparency, or lack thereof, in big data sets like mobile device data. ${ }^{23}$ This poses not only analytical issues but also issues of ethics and reproducibility; that is why, for this research, we examined the mobile device and survey data along with data from pneumatic tube counters (PTCs), which may be considered as direct observations of traffic volumes rather than estimates based on sampled data. PTCs are one of the most common methods of collecting data on average daily traffic (ADT). These devices use two pressurized rubber hoses laid across a roadway, registering a vehicle when it drives over the hose. Many of these devices also have classification abilities, to collect more specific information about the quantity and types of vehicles using a particular route. Although PTCs are ubiquitous, there is surprisingly little research on their overall accuracy and reliability. McGowen and Sanderson compared hand-counts to PTC data at four project sites in Montana, and found that the total error-the difference between PTC and hand count, divided by hand count-was around 4 percent for these sites. ${ }^{24}$ Similarly, a 2014 study examining a variety of traffic counting methods in Minnesota calculated that approximately seven percent of measurements conducted with a PTC disagreed with those of loop-piezo-piezoloop (LPPL) road detectors, which detect vehicles though permanent magnetic loops installed in the road rather than with temporary pneumatic tubes laid across the surface of the road. ${ }^{25}$ Finally, Weible examined the accuracy of these devices when placed in various orientations along the roadway (i.e., slanted or perpendicular placement on the roadway). ${ }^{26}$ PTCs installed perpendicular to the roadway performed best at 0.85 percent total error (the difference between manual counts and PTC divided manual counts) while some slanted orientations produced errors as large as 18.5 percent. 
Based on the aforementioned findings from the literature review, this work proceeded with three different sources of data. These sources provided some information that could be compared among survey data, mobile device data, and PTC data, and provided some measures of the robustness of the estimates.

\section{DATA COLLECTION DETAILS}

This chapter compares the results from the recent survey with the estimates obtained from the mobile-device data from StreetLight Inc. (StreetLight Data or SLD) and Pneumatic Tube Count (PTC) data collected by the authors of this paper. PTCs were placed at the three primary entrance and exits to campus, as shown in Figure 18. These were left in place for a five-day period, from Monday, May 21, 2018 to May 25, 2018, which was the business week referred to in the survey. Counts were recorded on an hourly basis and were also classified by transportation mode. Note that Longview Lane is accessible only by bike. Counters were placed there (as shown in Figure 18) to collect bicycle volumes, but it was not included in the analysis of vehicular traffic.

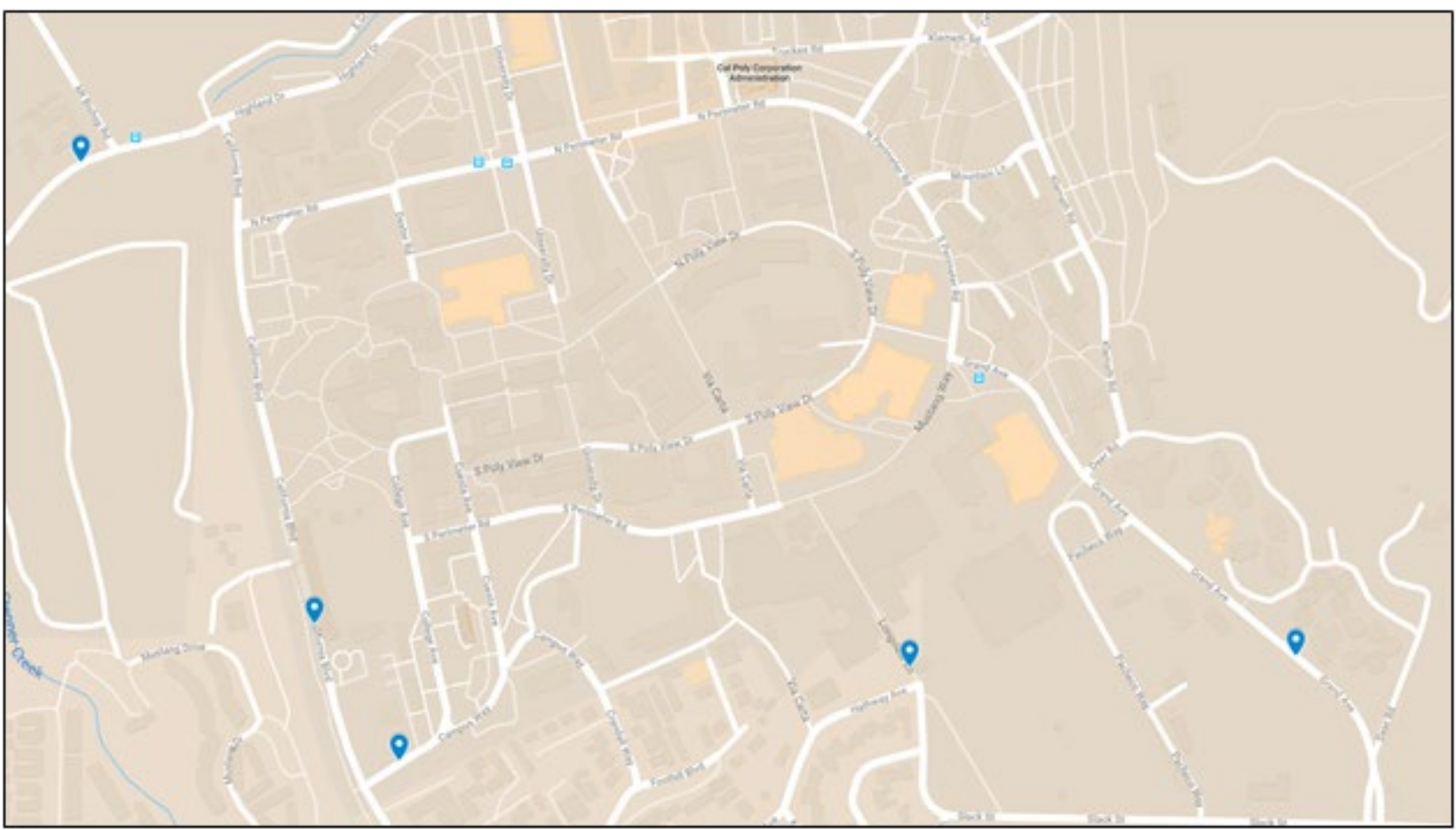

Figure 18. Approximate Positioning of the PTCs

In a similar manner, an analysis was conducted using the SLD platform, with zones defined at approximately the same location as the PTCs to allow for direct comparison (Figure 19). At each location, a "zone" was created using the SLD mapping tool. In order to mimic the PTC, we used a small rectangular polygon as a zone. With such a small zone, any detected trips should represent a pass-through trip, thus acting as a screen line providing counts analogous to the PTCs. In Figure 20, the red box represents the "zone" or a screen line for the Highland Dr location shown on the extreme left of Figure 19. Note that all "zones" in this study were defined as bidirectional zones, meaning that the SLD counts obtained for each "zone" contain pass-through trips in both directions, with no differentiation between inbound and outbound trips. 


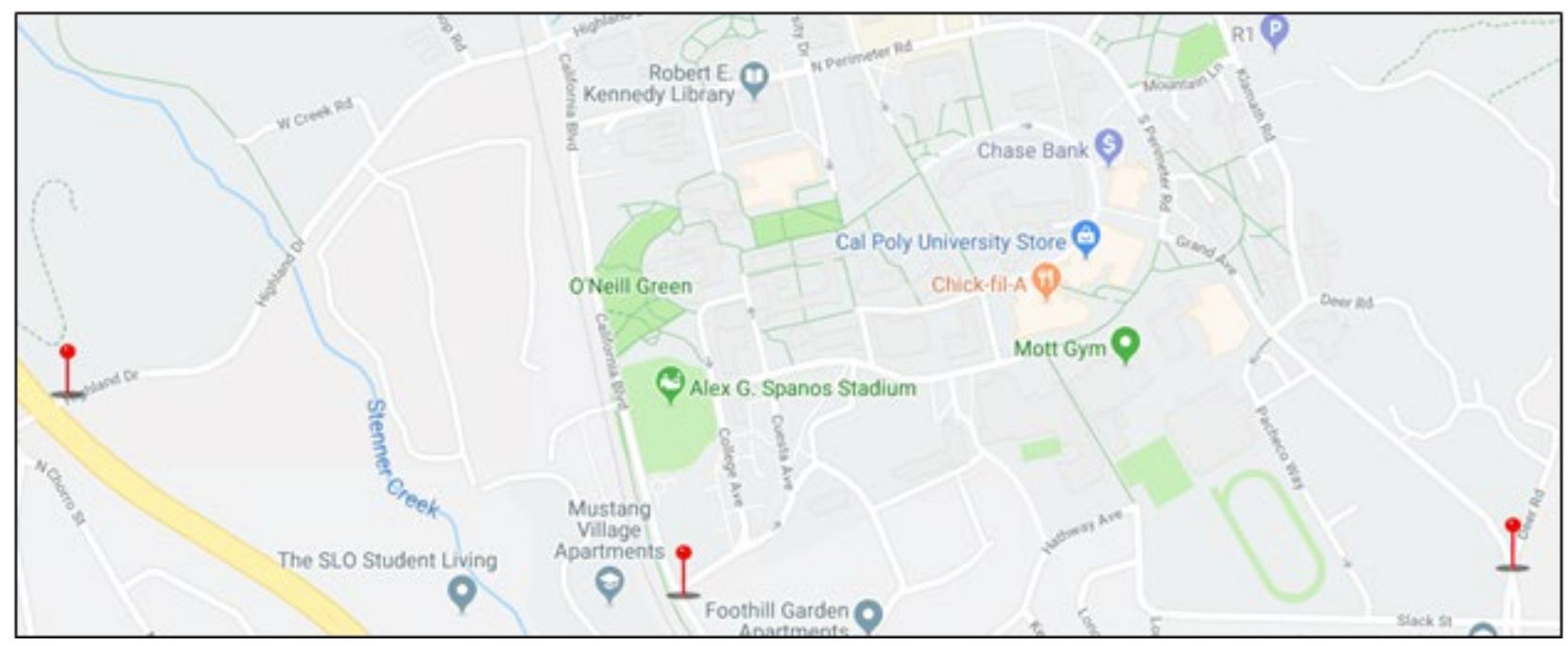

Figure 19. Location of SLD "Zones" or Screen Line

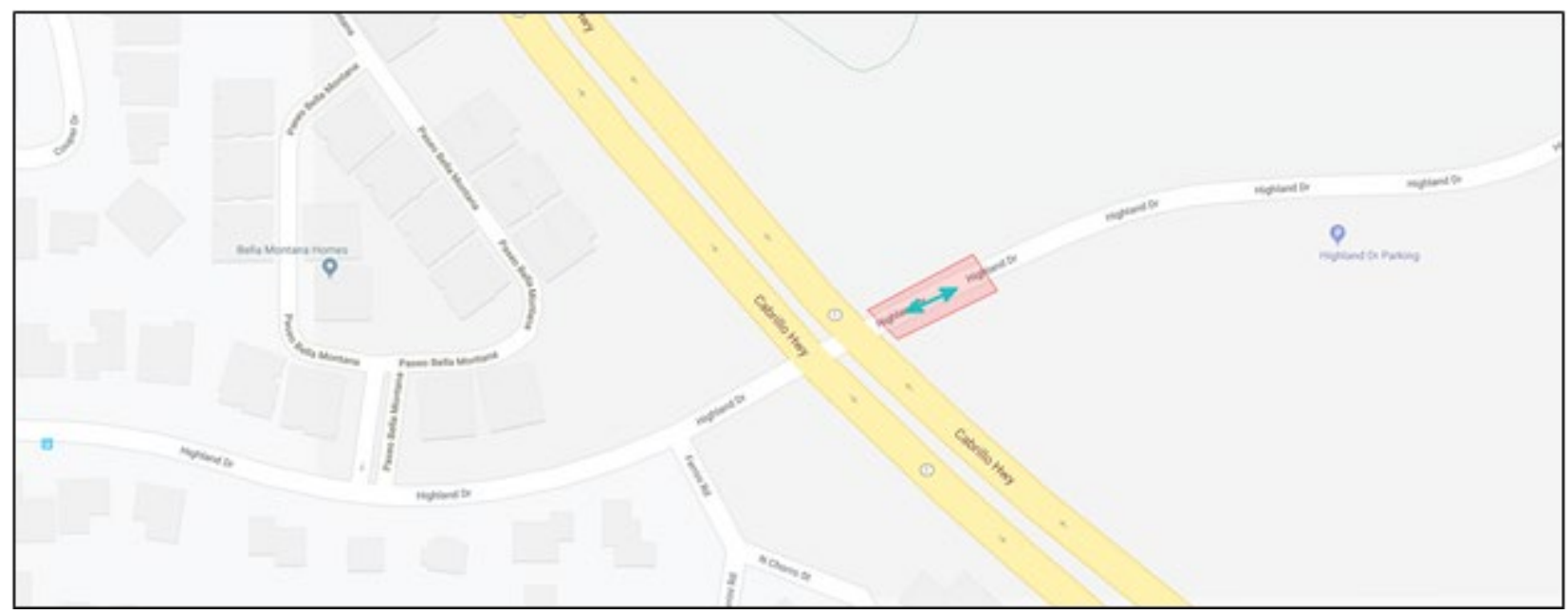

Figure 20. Screen Capture of the SLD Zone Mapping Interface

The results from the PTC and SLD can be compared with the survey data results, potentially augmenting the information obtained from each source.

\section{RESULTS}

Table 2 summarizes the important respondent categories used in estimating VMT from the survey data. Here, the number of responses received (i.e., the sample size) and the total reported population for each category is used to estimate the weight assigned to each response from that user group. The process is akin to the one used to estimate weights based on demographic characteristics of the respondents (such as age, race, and income level) in most other surveys. These faculty/staff/student categories were deemed to represent the greatest difference in commuting habits and are therefore used herein. Note that this is a simplified weighting method that results in slightly different weights than the ones used in Chapter 2. The more detailed weighting method presented in Chapter 2 was required to make more reliable comparisons among campus subpopulations. 
Table 2. Travel Survey Response Summary

\begin{tabular}{rcccc}
\hline Respondent Category & Number of Responses & Reported Population $^{1}$ & Response Rate & Response Weight \\
\hline Faculty, Full-time & 214 & 822 & $26.03 \%$ & 3.84 \\
Faculty, Part-time & 56 & 596 & $9.40 \%$ & 10.64 \\
Staff, Full-time & 544 & 1,138 & $47.80 \%$ & 2.09 \\
Staff, Part-time $^{\text {st }}$ & 22 & 532 & $4.14 \%$ & 24.18 \\
Undergraduate, $^{\text {st }}$ Year & 239 & 5,253 & $4.55 \%$ & 21.98 \\
Undergraduate, $^{\text {nd }}+$ Year & 1,306 & 16,044 & $8.14 \%$ & 12.28 \\
Graduate & 80 & 891 & $8.98 \%$ & 11.14 \\
Total & 2,461 & 25,276 & $9.74 \%$ & - \\
\hline
\end{tabular}

${ }^{1}$ Reported figures from Spring Quarter of 2017-2018 academic year

The weighted survey data can be used to determine the number of trips undergone by driving alone, and to estimate the total vehicular traffic at each campus entrance/exit (estimated based on another question in the survey) for each day of the week, allowing us to compare the data from the survey, PTCs, and SLD as shown in Table 3. Although the numbers do not match exactly, it can be seen that estimates from all the data sources have similar daily patterns. The aggregate/total counts for PTC and SLD are also similar. This provides some evidence of the validity of the survey data. There is a noticeable divergence in the results between the PTC and SLD values for California Boulevard and Grand Avenue; however, the divergence is consistent with Turner's finding that mobile device data tends to overestimate traffic volumes, relative to observations collected by traditional traffic counting devices. ${ }^{27}$

\section{Table 3. Comparison of Total Trip Generation Values By Data Source}

\begin{tabular}{rcrrrrr}
\hline \multirow{3}{*}{ Street } & & \multicolumn{5}{c}{ Automobiles } \\
\cline { 2 - 6 } California & Source & Mon & Tue & Wed & Thu & \multicolumn{1}{c}{ Fri } \\
& Survey & 452 & 506 & 511 & 504 & 407 \\
& PTC & 5487 & 5864 & 5532 & 5546 & 4889 \\
& SLD & 8422 & 9261 & 9218 & 8056 & 7543 \\
Grand & Survey & 432 & 463 & 455 & 445 & 395 \\
& PTC & 6998 & 7367 & 7965 & 8582 & 8525 \\
& SLD & 5888 & 5950 & 6521 & 6509 & 6855 \\
& Survey & 261 & 293 & 286 & 279 & 215 \\
& Highland & 5412 & 5667 & 5946 & 5998 & 4800 \\
& SLD & 3956 & 4511 & 4645 & 4136 & 4293 \\
& Survey & 1,145 & 1,262 & 1,252 & 1,228 & 1,017 \\
& Total & 17,906 & 18,915 & 19,450 & 20,140 & 18,224 \\
& SLD & 18,266 & 19,722 & 20,384 & 18,701 & 18,691 \\
\hline
\end{tabular}

There are a reasons to expect differences among trip generation estimates based on data from SLD, PTCs, and survey results. Estimates from SLD and PTCs are designed to include all vehicles that enter and leave campus. In contrast, the campus travel survey only includes regularly occurring commute by members of the Cal Poly community (students, faculty, and staff). Additionally, for SLD, the platform only allows users to obtain the average of ADT values on the same day of the week for a given month (i.e., not specific days). 
The relationship between PTC and SLD data can be assessed by plotting the reported PTC and SLD values for each entrance and day, as shown in Figure 21, where the dashed line represents agreement between the two data sources, points above the dashed line indicate that SLD estimates were higher than PTC data, and points below the line indicate that SLD estimates were lower than PTC data. In contrast to Turner's finding that mobile device data consistently underreports traffic volumes, relative to data from automatic traffic counters, there is no clear trend here, possibly due in part to the small sample size of comparison (over just five days). ${ }^{28}$ In two thirds of instances, it would appear that the SLD estimate is lower than the PTC counts, and in the remaining one third the SLD estimate is higher. With differences that can range between around 1000-4000 vehicles, this raises concerns about the accuracy of the SLD data.

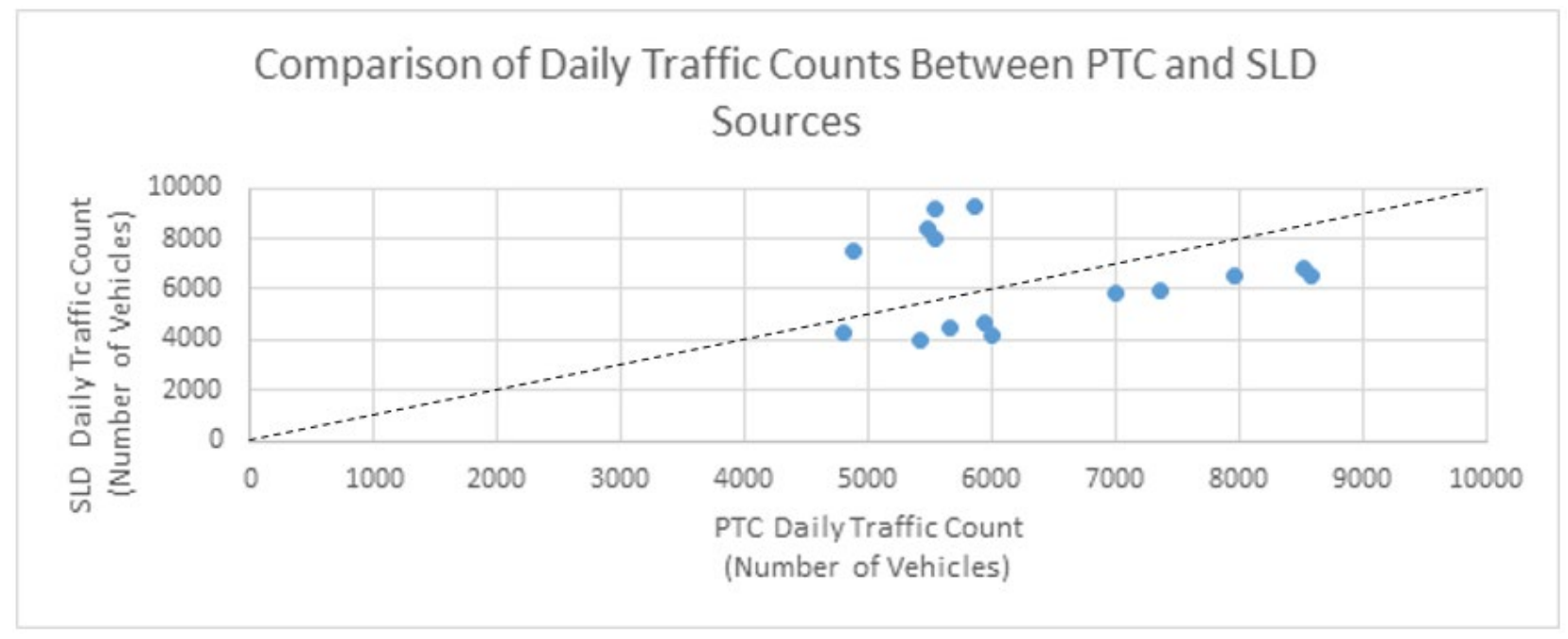

Figure 21. Relationship Between PTC and SLD Data Estimates

To be able to estimate the VMT, one also needs an estimate of the length of trips. Table 4 shows the reported proportion of trips with lengths in between the specified number of miles, for the SLD and for the survey data. This provides a discrete trip length distribution for each entrance as well as the average distance, in miles, of trips passing through each entrance. These results are also visualized in Figures 22-24, showing the values for each entrance/exit. Here, the discrepancies between the two values might be attributable to trips to and from campus by occasional campus visitors who are not Cal Poly students or employees and were thus not included in the survey data. Survey sampling error and SLD aggregation methods may also play a role. 


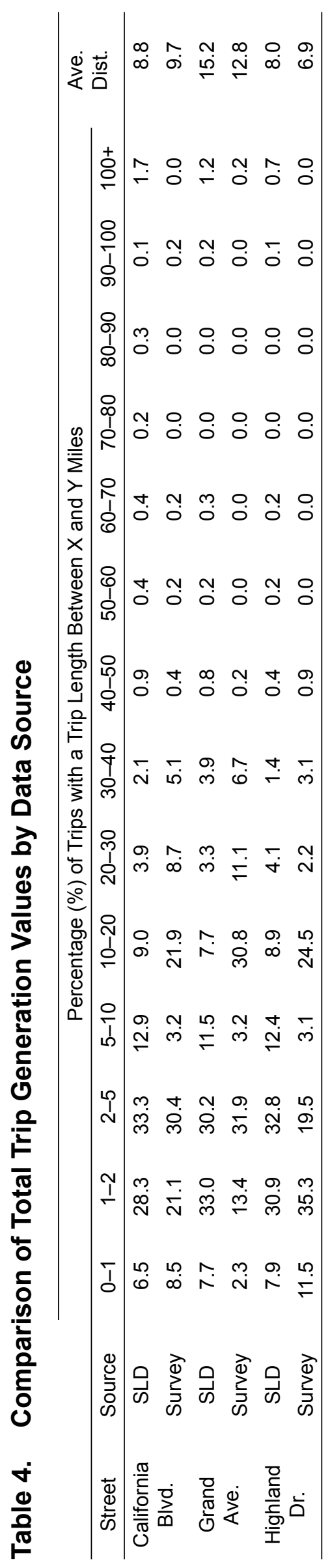




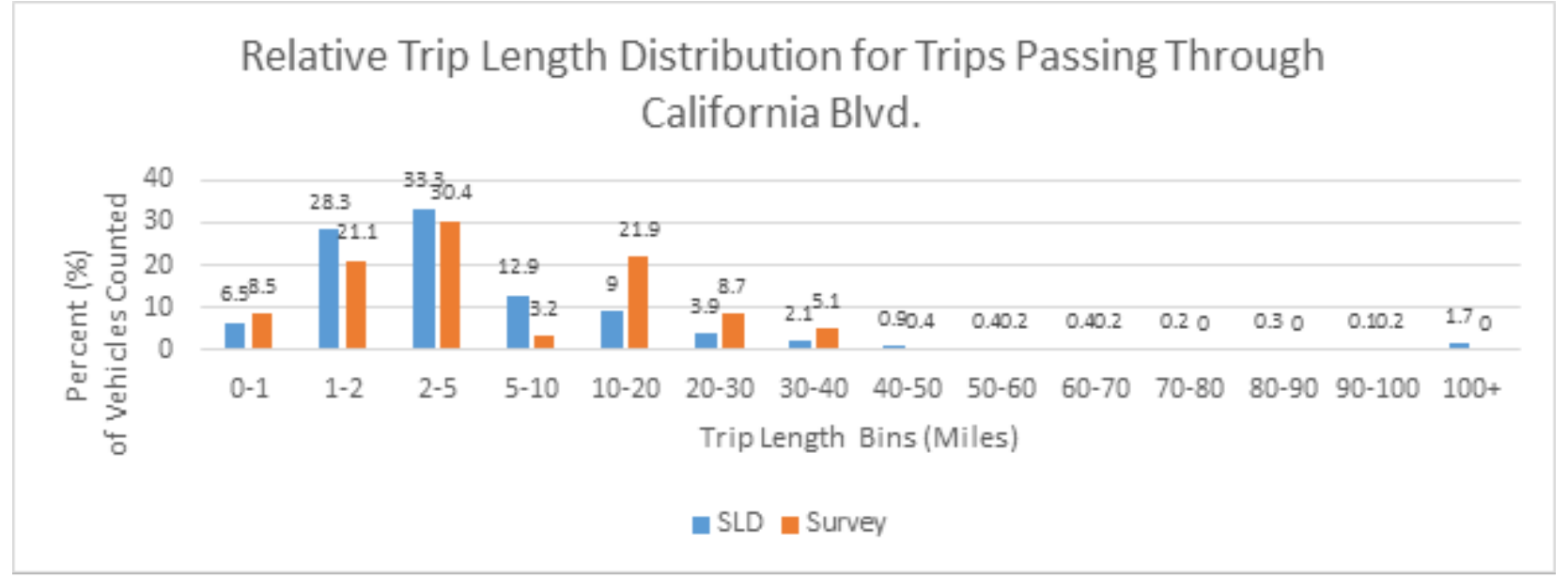

Figure 22. Proportional Trip Length Distribution at California Boulevard

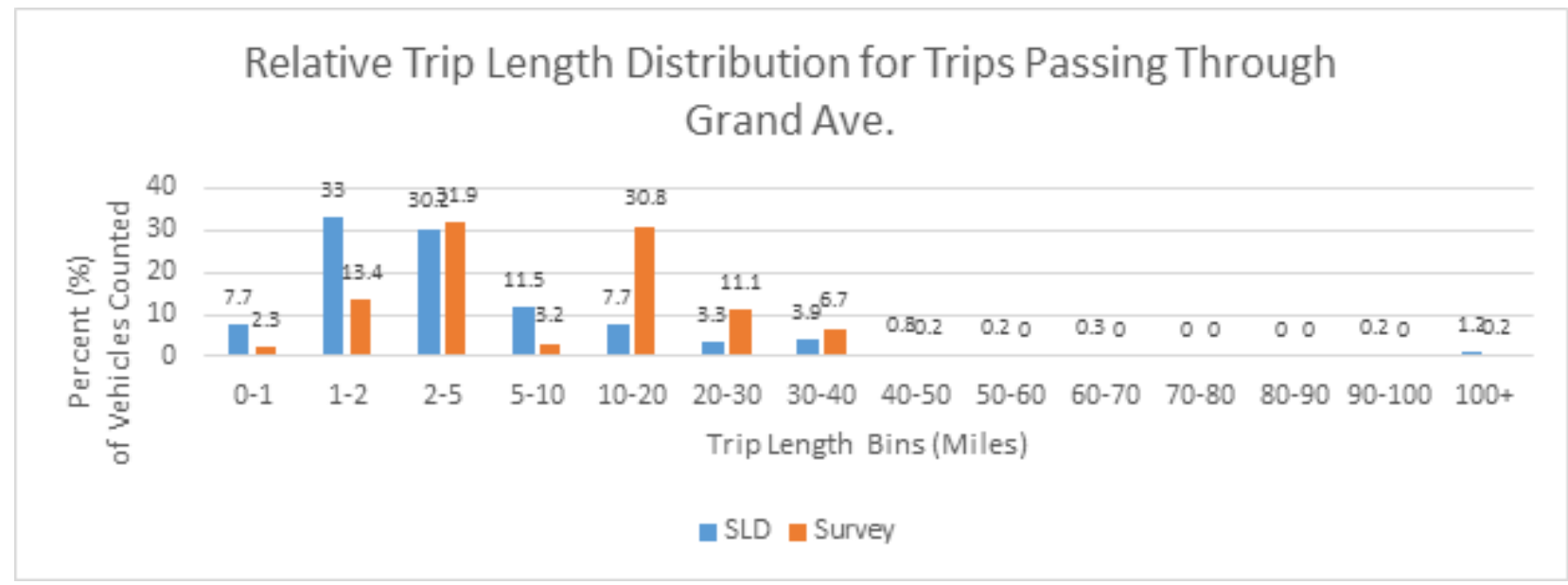

Figure 23. Proportional Trip Length Distribution at Grand Avenue

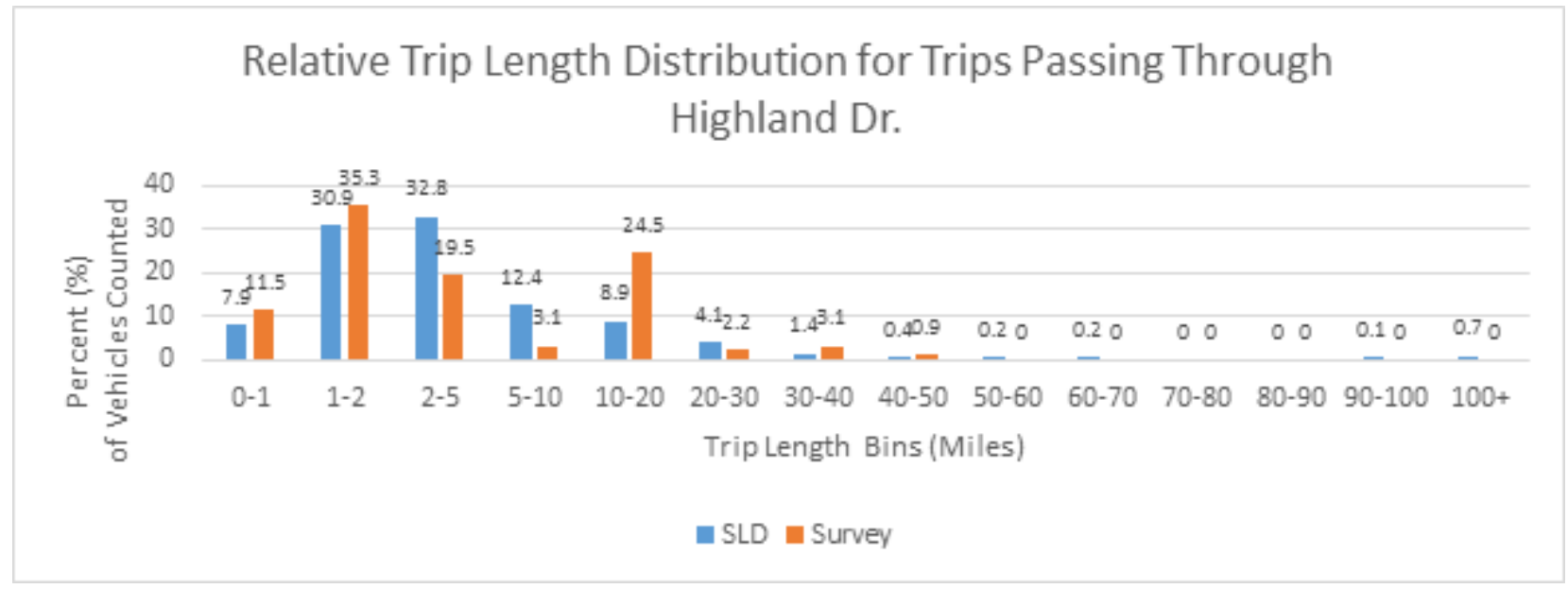

Figure 24. Proportional Trip Length Distribution at Highland Dr.

Finally, with the necessary inputs determined, VMT estimates were calculated by multiplying SLD trip generation by SLD trip lengths. The results are shown in Table 5 below. These 
show the cumulative number of annual VMT (in millions or MVMT) attributable to the role group and vehicle type driven, as well as the annual campus VMT per capita, and the percentage of total annual campus VMT attributable to each role group.

Table 5. Estimated VMT (in Millions) By Respondent Category and Vehicle Type

\begin{tabular}{rrrrrrrrrr}
\hline & \multicolumn{3}{c}{ Student } & \multicolumn{4}{c}{ Faculty and Staff } & \multicolumn{3}{c}{ All } \\
\hline & MVMT & $\begin{array}{c}\text { Per } \\
\text { Capita } \\
\text { VMT }\end{array}$ & $\begin{array}{c}\text { \% Total } \\
\text { VMT }\end{array}$ & MVMT & $\begin{array}{c}\text { Per } \\
\text { Capita } \\
\text { VMT }\end{array}$ & $\begin{array}{c}\text { \% Total } \\
\text { VMT }\end{array}$ & MVMT & $\begin{array}{c}\text { Per } \\
\text { Capita } \\
\text { VMT }\end{array}$ & $\begin{array}{c}\text { \% Total } \\
\text { VMT }\end{array}$ \\
\hline Gas & 39.73 & 1791 & $74.1 \%$ & 13.21 & 9316 & $24.6 \%$ & 52.93 & 2094 & $98.7 \%$ \\
Electric & 0.00 & 0 & $0.0 \%$ & 0.33 & 233 & $0.6 \%$ & 0.33 & 13 & $0.6 \%$ \\
Motorcycle & 0.21 & 9 & $0.4 \%$ & 0.16 & 113 & $0.3 \%$ & 0.37 & 15 & $0.7 \%$ \\
Total & 39.93 & 1800 & $74.5 \%$ & 13.69 & 9654 & $25.5 \%$ & 53.63 & 2122 & $100.0 \%$ \\
\hline
\end{tabular}

\section{DISCUSSION}

Our analysis yielded a VMT value of 53.63 million vehicle-miles generated by Cal Poly campus on an annual basis. Since the survey data are meant to capture a specific subset of trips to and from the Cal Poly campus, VMT and trip generation estimates from the PTC and SLD data are not directly comparable with the results of the campus travel survey. However, their differences do highlight important shortcomings of reliance on campus travel surveys to estimate campus-generated VMT. In particular, the survey will not capture trips by people who are not Cal Poly students or employees and therefore would not have taken the campus travel survey. While such individuals may travel to campus infrequently, their trips are commonly from larger metro areas such as San Francisco and Los Angeles, so they may have an outsized effect on VMT.

It is also difficult to compare this estimate with other campuses since most campuses do not have an easily accessible, public VMT estimate available. Table 6 shows VMT estimates from other campuses in California that we were able to locate, along with some characteristics that may contribute to variation in VMT.

Table 6. Comparative Campus Characteristics of Select Universities with Publicly Available VMT Estimates

\begin{tabular}{lccccc}
\hline \multicolumn{1}{c}{ Campus } & Year & $\begin{array}{c}\text { VMT } \\
\text { (Millions) }\end{array}$ & $\begin{array}{c}\text { Campus } \\
\text { Population }\end{array}$ & $\begin{array}{c}\text { Main Campus } \\
\text { Acreage }\end{array}$ & Other Considerations \\
\hline $\begin{array}{l}\text { Stanford University } \\
\begin{array}{l}\text { University of } \\
\text { California, Davis }\end{array}\end{array} 2015$ & $143.2^{1}$ & $38,851^{1}$ & $8,180^{3}$ & Many stadiums and venues plus a hospital \\
$\begin{array}{l}\text { Cal Poly } \\
2010\end{array}$ & $91.6^{2}$ & $40,209^{2}$ & $5,300^{4}$ & A high proportion of bicycle riders \\
\hline
\end{tabular}

References: ${ }^{1}$ Fehr \& Peers, 2017; ${ }^{2}$ Lovejoy, 2010; ${ }^{3}$ University, Stanford, \& California 94305, n.d.; 4 "Campus and Student Life at UC Davis | UC Davis Grad Studies," n.d.; 5 "Our Campus - About Cal Poly - Cal Poly, San Luis Obispo," n.d.

SLD and mobile device data, in general, hold great potential and in the future may grant researchers access to data otherwise not available by traditional means. As it relates to our research, one of the most promising aspects of SLD and other mobile device data services 
is the ability to define custom TAZs. This ability allowed us to define sub-zones within the campus so as to account for different entrances. One issue that may present itself in use of SLD for long-term travel pattern evaluation is that the underlying algorithm is always evolving and future revisions to the SLD algorithm may not yield the same results, even if no inputs have changed (e.g. if "zones," analysis method, times, etc. are the same). This could potentially make it difficult not only to reproduce results but also to compare future studies of those same areas.

Finally, in the case of the PTCs, it might be beneficial to take similar readings throughout the year-ideally at a high frequency, for example, once per quarter-to help account for potential seasonal effects. These proportions could be used to verify the survey results for each quarter (assuming the same proportion of trips each quarter would be attributable to Cal Poly students, faculty, and staff), to provide a better estimate of the campus VMT. 


\section{ESTIMATING GREENHOUSE GAS EMISSION FROM VEHICLE MILES TRAVELED}

Transportation is the largest source of greenhouse gas (GHG) emissions in California, contributing to 39 percent of total GHG emissions in $2016 .{ }^{29}$ Not surprisingly, transportation dominates the campus GHG inventory at Cal Poly, accounting for more than half of total GHG emissions. ${ }^{30}$ Accurately estimating GHG emissions of surface transportation requires a good understanding of vehicle characteristics, travel behaviors and emission rates under various conditions. Vehicle energy consumption and GHG emissions can be influenced by a number of factors, including: (1) activity (for example, the frequency and distance of one's commute); (2) system infrastructure and mode choice (for example, road conditions, urban form, and choosing to drive or take public transit for the commute); (3) vehicle and engine design and usage patterns (for example, gross vehicle weight and speed); and (4) fuel carbon intensity (for example, gasoline versus diesel). ${ }^{31}$ However, it is challenging to gather data on all these variables for a given institution, so analysts may rely on regional averages for GHG inventory analyses. Hereafter, these regional averages are referred to as aggregated emissions factors, and their use is referred to as an aggregated approach to GHG emissions estimation. Institutional travel surveys, including campus travel surveys that include questions about vehicle and trip characteristics allow for the use of separate emissions factors for each vehicle. Hereafter, these are referred to as disaggregated factors, and their use is referred to as a disaggregated approach.

In the previous chapters, we evaluate the effects of campus travel demand strategies and land use changes on the mode choice of students and employees on a university campus. In this chapter, we will focus on the GHG emissions resulting from those choices of commute transportation mode. For the GHG analysis, we use both the aggregated emission factors and the emission factors that are disaggregated by speed and vehicle model year and compare the results from using the two methods. The following sections describe the methods and data sources, and discuss the results and implications.

\section{METHODS AND DATA}

The travel mode choice data and weekly travel profiles were based on the travel survey that we conducted in 2018. Annual VMT was estimated by multiplying weekly travel distances by the number of weeks that employees and students spent commuting to campus. The commute period was assumed to be 46 weeks for faculty members and staff and 38 weeks for students. The GHG estimation is based on two methods (Eq. 1 and Eq. 2). The first method relies on aggregated emission factors that already factored in speed and vehicle model year. The second method takes into account the variations by speed and vehicle model year in calculating the emission factors. 


$$
\begin{array}{ll}
G H G_{1}=\sum_{r} \sum_{i, j}\left(V M T_{i, j} \cdot E F_{i, j}\right) & \ldots \text { Eq. } 1 \\
G H G_{2}=\sum_{r} \sum_{i, j, s, k}\left(V M T_{i, j, s, k} \cdot E F_{i, j, s, k}\right) & \ldots \text { Eq. } 2
\end{array}
$$

where

$$
\begin{aligned}
& i=\text { mode (10 modes in the survey) } \\
& j=\text { fuel type (gasoline, diesel or electricity) } \\
& s=\text { speed (from } 5 \text { to } 65 \mathrm{MPH} \text { ) } \\
& k=\text { vehicle model year (from } 1974 \text { to } 2018 \text { ) } \\
& r=\text { role on campus (students or faculty and staff) } \\
& \text { VMT = annual vehicle mile traveled } \\
& \text { EF = emission factors (gCO2e/mile) }
\end{aligned}
$$

The Emission Factor (EMFAC) model estimates on-road mobile vehicle emissions of major criterial pollutants and GHGs at various scales of geographic concentration in California. ${ }^{32}$ California state and local governments have used different versions of the EMFAC model for decision making on policies and programs to fulfill requirements under the Clean Air Act (CAA). Currently there are two versions of the EMFAC model: EMFAC2014 and EMFAC2017. The US EPA has approved the use of EMFAC2014 for the purposes of state implementation plan (SIP) and transportation conformity. ${ }^{33}$ The California Air Resources Board (CARB) has used EMFAC2017 for the on-road transportation sector in the 2018 edition of the statewide GHG emissions inventory. ${ }^{34}$ For cars and motorcycles, emission factors from both EMFAC2014 and EMFAC2017 were used for the GHG analysis. For business-related air travel, emissions factors were obtained from US EPA. ${ }^{35}$

The VMT breakdowns by fuel type and speed were obtained by multiplying total VMT estimates, calculated from the survey, by regional shares, obtained from the EMFAC model. The VMT breakdown by vehicle model year was based on the survey results. Estimates of GHG emissions will be organized by four categories: (1) Method 1, using EMFAC2014 emission factors and Eq. 1; (2) Method 2, using EMFAC2014 emission factors and Eq. 2; (3) Method 3, using EMFAC2017 emission factors and Eq. 1; (4) Method 4, using EMFAC2017 emission factors and Eq. 2.

\section{RESULTS AND DISCUSSION}

\section{VMT Estimation}

Given that active transportation modes, such as walking and bicycling, do not result in GHG emissions, annual VMT was estimated only for gas-powered vehicles. As indicated in previous chapters, the annual total VMT for 2018 was estimated to be 43.9 million 
miles, with students contributing to approximately 64 percent and faculty members and staff contributing to 36 percent of this total. The breakdown of VMT by vehicle model year within each group (Figure 25) indicate that 61.6 percent of students' distance traveled was completed by newer vehicles (manufactured on or after 2006), while 76.7 percent of distance traveled by faculty members and the staff was completed with newer vehicles. According to US national statistics, the average fuel efficiency of light-duty passenger vehicles has increased from 28 miles per gallon (mpg) in 1980 to $37.7 \mathrm{mpg}$ in 2016. ${ }^{36}$ Besides the differences in total VMT by campus role, the difference in VMT breakdowns by vehicle model year within the two groups will also directly affect GHG emissions.

Students

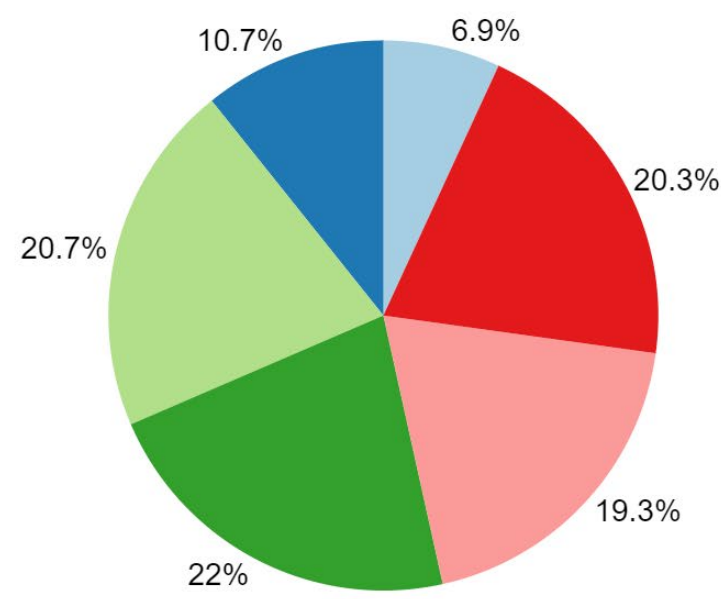

Prior to 1995

$1995-2000$

$2001-2005$

$2006-2010$

$2011-2015$

After 2015

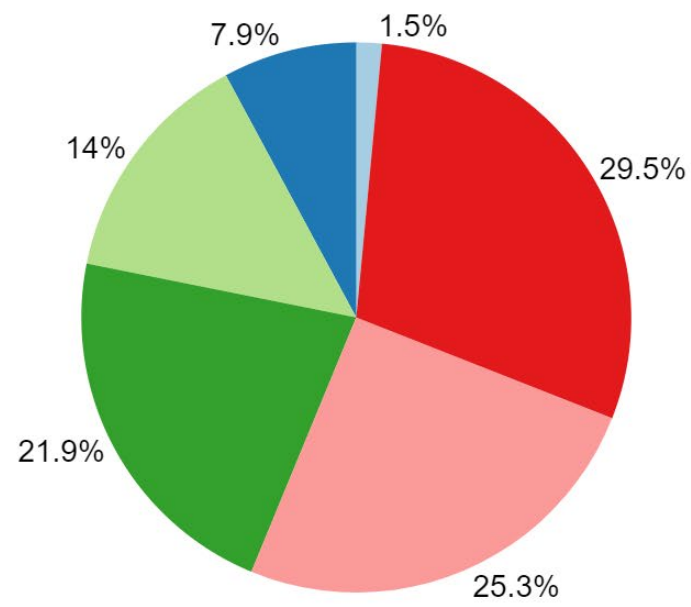

Figure 25. VMT Breakdowns for Non-PEV Light-Duty Vehicles by Vehicle Model Year

\section{GHG Emissions Estimation}

Total GHG emissions estimates range from 12406-13081 metric tons in $\mathrm{CO}_{2} \mathrm{e}$, depending on the specific estimation method used (Figure 26). Across all four sets of results, total emissions from students using gas-powered vehicles were consistently found to be the largest source of commute-related GHG emissions on campus. 


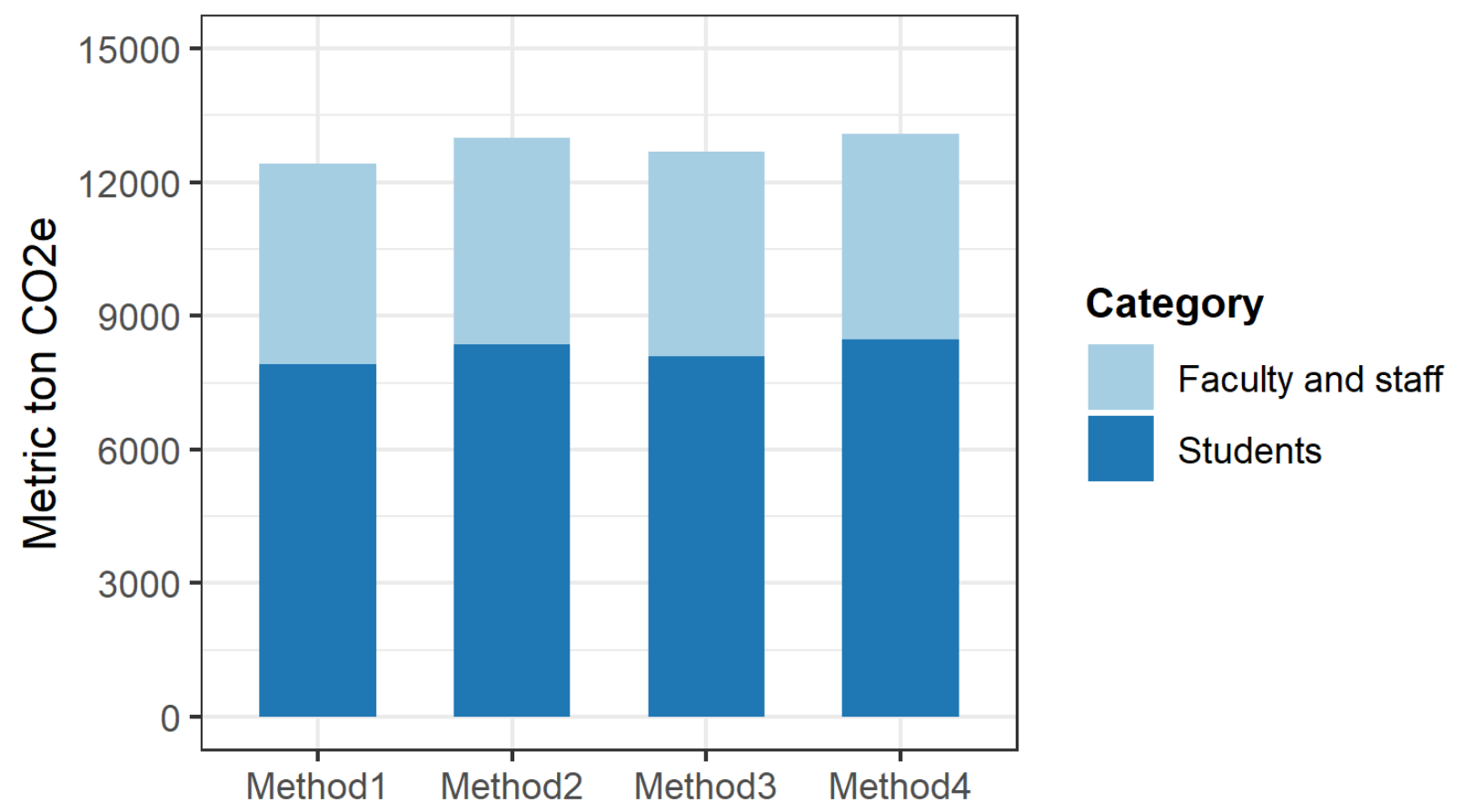

Figure 26. GHG Emissions Estimation by the Method

EMFAC2017 reported emissions factors for $\mathrm{N}_{2} \mathrm{O}, \mathrm{CH}_{4}$, and $\mathrm{CO}_{2}$, while EMFAC2014 only reported emission factors for $\mathrm{CO}_{2}$. The combined GHG emission factors in EMFAC2017 are slightly greater than those in EMFAC2014. This explains why Method 3 and Method 4 yields higher emissions than Method 1 and Method 2, respectively. Another difference originated from the decision whether to disaggregate VMT by speed and vehicle model year and use varying emission factors, or whether to use average emission factors. The disaggregated approach generally results in higher emissions estimates (Method 2 as compared to Method 1 and Method 4 as compared to Method 1).This suggests that the overall fleet of vehicles used for commuting to Cal Poly has a higher average GHG emission rate than the overall fleet of vehicles in the San Luis Obispo region. 


\section{CONCLUSION}

University campus travel surveys offer an opportunity to study a question critical to the future of sustainable mobility: do people make particular transportation choices because of the characteristics of the places where they live, or do they choose to live in a particular place because it allows them to make the transportation choices they prefer? Universities can relatively easily constrain students' residential location and commute transportation mode choices through implementation of parking and housing policies. This work attempted to estimate travel choices through survey data, complemented by mobile device data and PTC data.

\section{SUMMARY OF FINDINGS AND SUGGESTIONS FOR FUTURE WORK}

Between 2018 and 2019, the frequency of travel to campus by individual members of the campus community did not increase; the average commute distance increased by about one mile; and the share of commute trips taking place by single-occupancy vehicles increased from 35 percent to 46 percent. Combined, these changes resulted in a 30 percent increase in average weekly VMT per person, from 50 miles per person per week in 2018 to 65 miles per person per week in 2019. The restriction on on-campus parking for first-year students did reduce the share of first-year students driving alone to and from campus. Based on studies that suggest that experience with alternatives to driving alone makes people less car-dependent later in life, it was expected that this reduction in driving might persist into these students' second year, even once the restriction on on-campus parking was lifted; however, this was found not to be the case. ${ }^{37}$ Findings from mobile device data reveals that the travel survey may be underestimating the VMT, since it only includes regular (e.g. daily or weekly) commutes by members of the community, and does not account for occasional (and potentially long-distance) travel to the campus by people who are not affiliated with Cal Poly, such as campus visitors. These trips are relatively few, but are typically more than 100 miles long, originating from larger metro areas of Los Angeles or the San Francisco Bay Area. Some of these trips are by prospective students that may be captured through addition of survey questions that ask current students about their past visits to campus when they were still prospective students.

Johnson and Smith noted that there is an issue of a lack of transparency in big data sets, like those of mobile device data. ${ }^{38}$ This raises not only analytical issues but also issues of ethics and reproducibility. For this reason, for this research we examined the mobile device and survey data along with data from pneumatic tube counters (PTC). Future work in this area may include long-term count studies conducted over multiple academic terms. One issue that may present itself in use of SLD for long-term travel pattern evaluation is that the underlying algorithm is always evolving and future revisions to the SLD algorithm may not yield the same results, even if no inputs have changed (e.g. "zones," analysis method, times, etc. are the same). This could potentially make it difficult to not only reproduce results but also to compare future studies of those same areas. This may necessitate exploration of other mobile data sources beyond SLD. 


\section{ABBREVIATIONS AND ACRONYMS}

\begin{tabular}{ll}
\hline AADT & Annual Average Daily Traffic \\
ADT & Average Daily Traffic \\
CAA & Clean Air Act \\
CARB & California Air Resources Board \\
$\mathrm{CH}_{4}$ & Methane \\
$\mathrm{CO}_{2}$ & Carbon dioxide \\
$\mathrm{CO}_{2}$ e & Carbon dioxide equivalent \\
EMFAC & Emission Factor \\
EV & Electric Vehicle \\
GHG & Greenhouse Gas \\
LPPL & Loop-piezo-piezo-loop \\
MPO & Metropolitan planning organization \\
MVM & Million vehicle miless \\
N2O & Nitrous oxide \\
PEV & Plug-in electric vehicle \\
PTC & Pneumatic Tube Counter \\
SIP & State Implementation Plan \\
SLD & StreetLight Data \\
TAZ & Traffic Analysis Zone \\
TDM & Travel demand management \\
USDOT & United States Department of Transportation \\
US EPA & United States Environmental Protection Agency \\
VMT & Vehicle Miles Traveled \\
\hline
\end{tabular}




\section{ENDNOTES}

1. World Business Council for Sustainable Development \& World Resources Institute, "The Greenhouse Gas Protocol: A Corporate Accounting and Reporting Standard, Revised Edition" (Washington DC, 2015), https://ghgprotocol.org/sites/default/files/ standards/ghg-protocol-revised.pdf (accessed July 29, 2019).

2. Adrienne I. Greve, William Riggs, Kai Lord Farmer, Lance Knox, Jana Schwartz, "California Polytechnic State University Greenhouse Gas Inventory," California Polytechnic State University Facilities Management \& Development (2017), https:// afd.calpoly.edu/sustainability/docs/poly\%20cap/polycap $\% 20 \mathrm{ghg} \% 20$ emissions $\% 20$ inventory4.26.17.pdf.

3. Carlos J. L. Balsas (2003), "Sustainable transportation planning on college campuses," Transport Policy 10, no. 1 (2003): 35-49, https://doi.org/10.1016/S0967070X(02)00028-8; John Daggett, and Richard Gutkowski, “University Transportation Survey: Transportation in University Communities," Transportation Research Record: Journal of the Transportation Research Board 1835 (2003): 42-49, https://doi. org/10.3141/1835-06

4. Alex Bond and Ruth L. Steiner, "Sustainable Campus Transportation through Transit Partnership and Transportation Demand Management: A Case Study from the University of Florida," Berkeley Planning Journal 19, no. 1 (2006), https://escholarship. org/uc/item/04b7c73h; Jennifer Bonham and Barbara Koth, "Universities and the cycling culture," Transportation Research Part D: Transport and Environment 15, no. 2 (2010): 94-102, https://doi.org/10.1016/j.trd.2009.09.006; Edmund J. Zolnik, "Cost Attribution in Unlimited Access Transit Programs: Case Study on the UConn Prepaid Fare Program Failure," The Professional Geographer 59, no. 3 (2007): 365-377, https://doi.org/10.1111/j.1467-9272.2007.00619.x.

5. Gulsah Akar and Kelly J. Clifton, "Influence of Individual Perceptions and Bicycle Infrastructure on Decision to Bike," Transportation Research Record: Journal of the Transportation Research Board 2140 (2009): 165-172, https://doi.org/10.3141/214018; Gulsah Akar, Chris Flynn, and Mi Namgung, "Travel Choices and Links to Transportation Demand Management: Case Study at Ohio State University," Transportation Research Record: Journal of the Transportation Research Board 2319 (2012): 77-85, https://doi.org/10.3141/2319-09; Eric M. Delmelle and Elizabeth Cahill Delmelle, "Exploring spatio-temporal commuting patterns in a university environment," Transport Policy 21 (2012): 1-9, https://doi.org/10.1016/j.tranpol.2011.12.007; David H. Kaplan, "Transportation sustainability on a university campus," International Journal of Sustainability in Higher Education 16, no. 2 (2015): 173-186, https:// doi.org/10.1108/IJSHE-03-2013-0023; Kai Lord-Farmer, William W. Riggs, and Adrienne I. Greve, "Transportation Policy for Campus Climate Action Planning: Process and Policy Implications," (paper presented at the 97th Annual Meeting of the Transportation Research Board, Washington DC, 2017), http://amonline.trb. org/63532-trb-1.3393340/t009-1.3408027/563-1.3408206/17-06686-1.3399837/1706686-1.3506042; William Riggs, "Dealing with parking issues on an urban campus: 
The case of UC Berkeley," Case Studies on Transport Policy 2, no. 3 (2014): 168176, https://doi.org/10.1016/j.cstp.2014.07.009; Tya Shannon, Billie Giles-Corti, Terri Pikora, Max Bulsara, Trevor Shilton, and Fiona Bull, "Active commuting in a university setting: Assessing commuting habits and potential for modal change," Transport Policy 13, no. 3 (2006): 240-253, https://doi.org/10.1016/j.tranpol.2005.11.002; Xin Wang, Asad J. Khattak, and Sanghoon Son, "What Can Be Learned from Analyzing University Student Travel Demand?" Transportation Research Record: Journal of the Transportation Research Board 2322 (2012): 129-137, https://doi.org/10.3141/232214; Jiangping Zhou, "Sustainable commute in a car-dominant city: Factors affecting alternative mode choices among university students," Transportation Research Part A: Policy and Practice 46, no. 7 (2012): 1013-1029, https://doi.org/10.1016/j. tra.2012.04.001.

6. Kai Lord-Farmer, William W. Riggs, and Adrienne I. Greve, "Transportation Policy for Campus Climate Action Planning: Process and Policy Implications," (paper presented at the 97th Annual Meeting of the Transportation Research Board, Washington DC, 2017), http://amonline.trb.org/63532-trb-1.3393340/t009-1.3408027/5631.3408206/17-06686-1.3399837/17-06686-1.3506042.

7. Patricia L. Mokhtarian and Xinyu Cao, "Examining the impacts of residential selfselection on travel behavior: A focus on methodologies," Transportation Research Part B: Methodological 42, no. 3 (2008): 204-228; Chandra R. Bhat and Naveen Eluru, "Acopulabased approach to accommodate residential self-selection effects in travel behavior modeling," Transportation Research Part B: Methodological 43, no. 7 (2009): 749-765; Bin Zhou and Kara M. Kockelman, "Self-selection in home choice: Use of treatment effects in evaluating relationship between built environment and travel behavior," Transportation Research Record 2077, no. 1 (2008): 54-61; Xinyu Cao, Susan L. Handy, and Patricia L. Mokhtarian "The influences of the built environment and residential self-selection on pedestrian behavior: evidence from Austin, TX," Transportation 33, no. 1 (2006): 1-20; Xinyu Cao, Patricia L. Mokhtarian, and Susan L. Handy, "Examining the impacts of residential self-selection on travel behaviour: a focus on empirical findings," Transport reviews 29, no. 3 (2009): 359-395.

8. Michael J. Smart and Nicholas J. Klein, "Remembrance of cars and buses past: How prior life experiences influence travel," Journal of Planning Education and Research 38, no. 2 (2018): 139-151.

9. David Cooley, "Package 'googleway'," The Comprehensive R Archive Network, https:// cran.rstudio.com/web/packages/googleway/googleway.pdf

10. Robert M. Groves, "Nonresponse rates and nonresponse bias in household surveys," Public opinion quarterly 70, no. 5 (2006): 646-675.

11. Michael J. Smart and Nicholas J. Klein, "Remembrance of cars and buses past: How prior life experiences influence travel," Journal of Planning Education and Research 38, no. 2 (2018): 139-151. 
12. Amy Lee, Kevin Fang and Susan Handy, "Evaluation of Sketch-Level VMT Quantification Tools: Strategic Growth Council Grant Programs Evaluation Support Project," National Center for Sustainable Transportation (2017), https://ncst.ucdavis. edu/wp-content/uploads/2017/06/NCST-SGC_Handy-VMT-Quant_Final-ReportAUGUST-2017.pdf; Thomas A. Williams, Byron Chigoy, Jeff Borowiec, and Brianne Glover, "Methodologies Used to Estimate and Forecast Vehicle Miles Traveled (VMT)" (No. PRC 15-40 F), Texas A\&M Transportation Institute (2016), https://static.tti.tamu. edu/tti.tamu.edu/documents/PRC-15-40-F.pdf.

13. M. Shahid Mamun, Yafeng Yin, and Sivaramakrishnan Srinivasan (2010), "Trip Generation Characteristics of Special Generators" (No. TRC-FDOT-76173-2009), Transportation Research Center, University of Florida (2010), http://www.fsutmsonline. net/images/uploads/reports/FDOT_BDK77_977-01_rpt.pdf.

14. Ibid.

15. Venu M. Garikapati, Daehyun You, Ram M. Pendyala, Tushar Patel, Jiji Kottommannil, and Aaron Sussman, "Design, Development, and Implementation of a University Travel Demand Modeling Framework," Transportation Research Record: Journal of the Transportation Research Board 2563 (2016): 105-113, https://doi. org/10.3141/2563-15.

16. Asad Khattak, Xin Wang, Sanghoon Son, and Paul Agnello, "Travel by University Students in Virginia: Is This Travel Different from Travel by the General Population?" Transportation Research Record 2255, no. 1 (2011): 137-145, https://doi. org/10.3141/2255-15; Maricopa Association of Governments, "Arizona State University Travel Survey and Model Update" (p. 185), http://www.azmag.gov/Portals/0/ Documents/TRANS_2015-07-27_Arizona-State-University-(ASU)-Travel-Surveyand-Model-Update.pdf.

17. CRP 410/411 Studio. (n.d.). Cal Poly Climate Action Plan. Retrieved from California Polytechnic State University website: https://afd.calpoly.edu/sustainability/docs/ poly\%20cap/polycap4.26.17.pdf.

18. David Cantor, Gary Shapiro, Li Wan Chen, G. Hussain Choudhry, and Mark Freedman, "Non-Response in the National Household Transportation Survey (NHTS)" (2004), in Transportation Research Board. National Household Travel Survey Conference, Washington, DC, November (pp. 1-2); Yiting Dai, Jill DeMatteis, and Shelley Brock Roth, "2017 NHTS Weighting Report" (2017): p. 53, Westat.

19. Cheryl Stecher and Peter Stopher (Eds.), Travel Survey Methods (Emerald Group Publishing, 2006), https://doi.org/10.1108/9780080464015; Johanna Zmud, Martin Lee-Gosselin, Juan Antonio Carrasco, and Marcela A. Munizaga, Transport Survey Methods (Emerald Group Publishing, 2013), https://books.emeraldinsight. com/page/detail/transport-survey-methods-by-johanna-zmudTransport-SurveyMethods/?k=9781781902875. 
20. Fehr \& Peers, Stanford 2018 General Use Permit: SB 743 VMT Analysis (No. SJ151585) (August 2017), https://www.sccgov.org/sites/dpd/DocsForms/Documents/ SU_2018GUP_App_Tab8_VMT.pdf.

21. Shawn Turner and Pete Koeneman, "Using Mobile Device Samples to Estimate Traffic Volumes" (No. MN/RC 2017-49), Minnesota Department of Transportation (2017), http://mndot.gov/research/reports/2017/201749.pdf.

22. Timothy P. Johnson and Tom W. Smith, "Big Data and Survey Research: Supplement or Substitute?" in Seeing Cities Through Big Data: Research, Methods and Applications in Urban Informatics (2017): pp. 113-125, https://doi.org/10.1007/9783-319-40902-3_7.

23. Ibid.

24. Patrick McGowen and Michael Sanderson, "Accuracy of Pneumatic Road Tube Counters" (paper presented at the Institute of Transportation Engineers (ITE) Western District Annual Meeting, 2011), https://trid.trb.org/view/1257430.

25. Michael Marti, Renae Kuehl, and ScottPetersen, "Traffic Data Collection Improvements" (2014), https://trid.trb.org/view/1308598.

26. Benjamin Weible, "Investigating the Impact of Skewed Pneumatic Traffic-Counting Tubes on Accuracy," Mid-Atlantic Transportation Sustainability University Transportation Center (July 2016), http://www.matsutc.org/wp-content/uploads/2016/07/Weible.pdf.

27. Shawn Turner and Pete Koeneman, "Using Mobile Device Samples to Estimate Traffic Volumes" (No. MN/RC 2017-49), Minnesota Department of Transportation (2017), http://mndot.gov/research/reports/2017/201749.pdf.

28. Ibid.

29. California Air Resources Board, "California Greenhouse Gas Emissions for 2000 to 2017: Trends of Emissions and Other Indicators, 2018 Edition" (2018), https://ww3. arb.ca.gov/cc/inventory/pubs/reports/2000_2016/ghg_inventory_trends_00-16.pdf, accessed July 30, 2019.

30. Adrienne I. Greve, William Riggs, Kai Lord Farmer, Lance Knox, And Jana Schwartz, "California Polytechnic State University Greenhouse Gas Inventory," California Polytechnic State University Facilities Management \& Development (2017), https:// afd.calpoly.edu/sustainability/docs/poly $\% 20$ cap/polycap $\% 20 \mathrm{ghg} \% 20 \mathrm{emissions} \% 20$ inventory4.26.17.pdf.

31. Ralph Sims et al., "Climate Change 2014: Mitigation of Climate Change," Contribution of Working Group III to the Fifth Assessment Report of the Intergovernmental Panel on Climate Change (Cambridge University Press, Cambridge, United Kingdom and New York, NY, USA, 2014), https://www.ipcc.ch/site/assets/uploads/2018/02/ipcc_ 
wg3_ar5_full.pdf

32. California Air Resources Board, "Mobile Source Emissions Inventory" (2019), https:// ww3.arb.ca.gov/msei/msei.htm, accessed July 30, 2019.

33. California Air Resources Board, "EMFAC2014 (USEPA approved)" (2015), https:// ww3.arb.ca.gov/msei/categories.htm\#emfac2014, accessed July 30, 2019.

34. California Air Resources Board, "California Greenhouse Gas Emissions for 2000 to 2017: Trends of Emissions and Other Indicators, 2018 Edition" (2018), https://ww3. arb.ca.gov/cc/inventory/pubs/reports/2000_2016/ghg_inventory_trends_00-16.pdf, accessed July 30, 2019.

35. Ibid.

36. USDOT, "Average Fuel Efficiency of US Light Duty Vehicles," Bureau of Transportation Statistics, https://www.bts.gov/content/average-fuel-efficiency-us-light-duty-vehicles.

37. Michael J. Smart and Nicholas J. Klein, "Remembrance of cars and buses past: How prior life experiences influence travel," Journal of Planning Education and Research 38, no. 2 (2018): 139-151.

38. Timothy P. Johnson and Tom W. Smith, "Big Data and Survey Research: Supplement or Substitute?" in Seeing Cities Through Big Data: Research, Methods and Applications in Urban Informatics (2017): pp. 113-125, https://doi.org/10.1007/978-3-319-409023_7. 


\section{BIBLIOGRAPHY}

Akar, G., \& Clifton, K. (2009). Influence of Individual Perceptions and Bicycle Infrastructure on Decision to Bike. Transportation Research Record: Journal of the Transportation Research Board, 2140, 165-172. https://doi.org/10.3141/2140-18.

Akar, G., Flynn, C., \& Namgung, M. (2012). Travel Choices and Links to Transportation Demand Management: Case Study at Ohio State University. Transportation Research Record: Journal of the Transportation Research Board, 2319, 77-85. https://doi.org/10.3141/2319-09.

Alexander, L., Jiang, S., Murga, M., \& González, M. C. (2015). Origin-destination trips by purpose and time of day inferred from mobile phone data. Transportation Research Part C: Emerging Technologies, 58, 240-250. https://doi.org/10.1016/j. trc.2015.02.018.

Amy Lee, Kevin Fang, \& Susan Handy. (2017). Evaluation of Sketch-Level VMT Quantification Tools: Strategic Growth Council Grant Programs Evaluation Support Project. Retrieved from National Center for Sustainable Transportation website: https://ncst.ucdavis.edu/wp-content/uploads/2017/06/NCST-SGC_ Handy-VMT-Quant_Final-Report-AUGUST-2017.pdf.

Balsas, C. J. L. (2003). Sustainable transportation planning on college campuses. Transport Policy, 10(1), 35-49. https://doi.org/10.1016/S0967-070X(02)00028-8.

Bhat, C. R., \& Eluru, N. (2009). A copula-based approach to accommodate residential self-selection effects in travel behavior modeling. Transportation Research Part B: Methodological, 43(7), 749-765.

Bond, A., \& Steiner, R. (2006). Sustainable Campus Transportation through Transit Partnership and Transportation Demand Management: A Case Study from the University of Florida. Berkeley Planning Journal, 19(1). Retrieved from https:// escholarship.org/uc/item/04b7c73h.

Bonham, J., \& Koth, B. (2010). Universities and the cycling culture. Transportation Research Part D: Transport and Environment, 15(2), 94-102. https://doi. org/10.1016/j.trd.2009.09.006.

Calabrese, F., Lorenzo, G. D., Liu, L., \& Ratti, C. (2011). Estimating Origin-Destination Flows Using Mobile Phone Location Data. IEEE Pervasive Computing, 10(4), 36-44. https://doi.org/10.1109/MPRV.2011.41.

California Air Resources Board. (2015). "EMFAC2014 (USEPA approved)." https://ww3. arb.ca.gov/msei/categories.htm\#emfac2014. December 14, 2015. Accessed July 30, 2019.

California Air Resources Board. (2018). California Greenhouse Gas Emissions for 2000 
to 2016: Trends of Emissions and Other Indicators, 2018 Edition. https://ww3.arb. ca.gov/cc/inventory/pubs/reports/2000_2016/ghg_inventory_trends_00-16.pdf. Accessed July 30, 2019.

California Air Resources Board. (2019). Mobile Source Emissions Inventory. https://ww3. arb.ca.gov/msei/msei.htm. February 27, 2019. Accessed July 30, 2019.

Campus and Student Life at UC Davis | UC Davis Grad Studies. (n.d.). Retrieved June 5, 2019, from https://grad.ucdavis.edu/admissions/why-uc-davis/campus-andstudent-life.

Cantor, D., Shapiro, G., Chen, L., Choudhry, G., \& Freedman, M. (2004). Non-Response in the National Household Transportation Survey (NHTS). In Transportation Research Board. National Household Travel Survey Conference, Washington, DC, November (pp. 1-2).

Cao, X., Handy, S. L., \& Mokhtarian, P. L. (2006). The influences of the built environment and residential self-selection on pedestrian behavior: evidence from Austin, TX. Transportation, 33(1), 1-20.

Cao, X., Mokhtarian, P. L., \& Handy, S. L. (2009). Examining the impacts of residential self-selection on travel behaviour: a focus on empirical findings. Transport reviews, 29(3), 359-395.

Cooley, David. (2018). Package 'googleway'. The Comprehensive R Archive Network. Retrieved from https://cran.rstudio.com/web/packages/googleway/googleway.pdf.

CRP 410/411 Studio. (n.d.). Cal Poly Climate Action Plan. Retrieved from California Polytechnic State University website: https://afd.calpoly.edu/sustainability/docs/ poly\%20cap/polycap4.26.17.pdf.

Daggett, J., \& Gutkowski, R. (2003). University Transportation Survey: Transportation in University Communities. Transportation Research Record: Journal of the Transportation Research Board, 1835, 42-49. https://doi.org/10.3141/1835-06.

Delmelle, E. M., \& Delmelle, E. C. (2012). Exploring spatio-temporal commuting patterns in a university environment. Transport Policy, 21, 1-9. https://doi.org/10.1016/j. tranpol.2011.12.007.

DOT, U. (2018). Average Fuel Efficiency of US Light Duty Vehicles. Bureau of Transportation Statistics (Https://Bts. Gov/Content/Average-Fuel-Efficiency-UsLight-Duty-Vehicles).

EPA, U. (2017). Center for Corporate Climate Leadership GHG Emission Factors Hub.

Fehr \& Peers. (2017). Stanford 2018 General Use Permit: SB 743 VMT Analysis (No. SJ15-1585). Retrieved from https://www.sccgov.org/sites/dpd/DocsForms/ 
Documents/SU_2018GUP_App_Tab8_VMT.pdf.

Garikapati, V., You, D., Pendyala, R., Patel, T., Kottommannil, J., \& Sussman, A. (2016). Design, Development, and Implementation of a University Travel Demand Modeling Framework. Transportation Research Record: Journal of the Transportation Research Board, 2563, 105-113. https://doi.org/10.3141/2563-15.

Greve, A., Riggs, W., Lord-Farmer, K., Knox, L., \& Schwartz, J. (2017). California Polytechnic State University Greenhouse Gas Inventory. Retrieved from California Polytechnic State University Facilities Management \& Development website: https://afd.calpoly.edu/sustainability/docs/poly\%20cap/polycap $\% 20 \mathrm{ghg} \% 20$ emissions\%20inventory4.26.17.pdf.

Groves, R. M. (2006). Nonresponse rates and nonresponse bias in household surveys. Public opinion quarterly, 70(5), 646-675.

Jacobsen, P. L. (2003). Safety in numbers: More walkers and bicyclists, safer walking and bicycling. Injury Prevention, 9(3), 205-209. https://doi.org/10.1136/ip.9.3.205.

Johnson, T. P., \& Smith, T. W. (2017). Big Data and Survey Research: Supplement or Substitute? In Seeing Cities Through Big Data: Research, Methods and Applications in Urban Informatics (pp. 113-125). https://doi.org/10.1007/978-3319-40902-3_7.

Kaplan, D. H. (2015). Transportation sustainability on a university campus. International Journal of Sustainability in Higher Education, 16(2), 173-186. https://doi. org/10.1108/IJSHE-03-2013-0023.

Khattak, A., Wang, X., Son, S., \& Agnello, P. (2011). Travel by University Students in Virginia: Is This Travel Different from Travel by the General Population? Transportation Research Record, 2255(1), 137-145. https://doi.org/10.3141/225515.

Lord-Farmer, K., Riggs, W., \& Greve, A. (2017). Transportation Policy for Campus Climate Action Planning: Process and Policy Implications. 97th Annual Meeting of the Transportation Research Board. Presented at the 97th Annual Meeting of the Transportation Research Board, Washington DC. Retrieved from http:// amonline.trb.org/63532-trb-1.3393340/t009-1.3408027/563-1.3408206/17-066861.3399837/17-06686-1.3506042.

Lovejoy, K. (2010). Results of the 2009-10 Campus Travel Survey (No. UCD-ITSRR-10-17). Retrieved from https://its.ucdavis.edu/research/publications/?frame=ht tps $\% 3 \mathrm{~A} \% 2 \mathrm{~F} \% 2 \mathrm{Fitspubs}$.ucdavis.edu\%2Findex.php\%2Fresearch\%2Fpublications \%2Fpublication-detail\%2F\%3Fpub_id\%3D1409.

Mamun, M. S., Yin, Y., \& Srinivasan, S. (2010). Trip Generation Characteristics of Special Generators (No. TRC-FDOT-76173-2009). Retrieved from Transportation 
Research Center, University of Florida website: http://www.fsutmsonline.net/ images/uploads/reports/FDOT_BDK77_977-01_rpt.pdf.

Maricopa Association of Governments. (n.d.). Arizona State University Travel Survey and Model Update (p. 185). Retrieved from http://www.azmag.gov/Portals/0/ Documents/TRANS_2015-07-27_Arizona-State-University-(ASU)-Travel-Surveyand-Model-Update.pdf.

Marti, M., Kuehl, R., \& Petersen, S. (2014). Traffic Data Collection Improvements. Retrieved from https://trid.trb.org/view/1308598.

McGowen, P., \& Sanderson, M. (2011, May). Accuracy of Pneumatic Road Tube Counters. Presented at the Institute of Transportation Engineers (ITE). Western District Annual Meeting, 2011. Retrieved from https://trid.trb.org/view/1257430.

Megenbir, L. E., \& Habib, M. A. (2015). Estimating Fuel Consumption and Vehicle Emissions Using Multi-Year Travel Survey Data. Presented 94th Annual Meeting of the Transportation Research Board. Retrieved from https://trid.trb.org/ view/1339520.

Mokhtarian, P. L., \& Cao, X. (2008). Examining the impacts of residential self-selection on travel behavior: A focus on methodologies. Transportation Research Part B: Methodological, 42(3), 204-228.

Our Campus - About Cal Poly - Cal Poly, San Luis Obispo. (n.d.). Retrieved June 5, 2019, from https://www.calpoly.edu/aboutcp/our_campus.html.

Riggs, W. (2014). Dealing with parking issues on an urban campus: The case of UC Berkeley. Case Studies on Transport Policy, 2(3), 168-176. https://doi. org/10.1016/j.cstp.2014.07.009

Shannon, T., Giles-Corti, B., Pikora, T., Bulsara, M., Shilton, T., \& Bull, F. (2006). Active commuting in a university setting: Assessing commuting habits and potential for modal change. Transport Policy, 13(3), 240-253. https://doi.org/10.1016/j. tranpol.2005.11.002

Sims R., R. Schaeffer, F. Creutzig, X. Cruz-Núñez, M. D’Agosto, D. Dimitriu, M.J. Figueroa Meza, L. Fulton, S. Kobayashi, O. Lah, A. McKinnon, P. Newman, M. Ouyang, J.J. Schauer, D. Sperling, and G. Tiwari. (2014). Transport. In: Climate Change 2014: Mitigation of Climate Change. Contribution of Working Group III to the Fifth Assessment Report of the Intergovernmental Panel on Climate Change [Edenhofer, O., R. Pichs-Madruga, Y. Sokona, E. Farahani, S. Kadner, K. Seyboth, A. Adler, I. Baum, S. Brunner, P. Eickemeier, B. Kriemann, J. Savolainen, S. Schlömer, C. von Stechow, T. Zwickel and J.C. Minx (eds.)]. Cambridge University Press, Cambridge, United Kingdom and New York, NY, USA.Available at: https://www.ipcc.ch/site/assets/uploads/2018/02/ipcc_wg3_ar5_full.pdf 
Smart, M. J., \& Klein, N. J. (2018). Remembrance of cars and buses past: How prior life experiences influence travel. Journal of Planning Education and Research, 38(2), $139-151$.

Stecher, C., \& Stopher, P. (Eds.). (2006). Travel Survey Methods. https://doi. org/10.1108/9780080464015

Thigpen, C. G. (2017). The Reciprocal Relationship between Children and Young Adults' Travel Behavior and Their Travel Attitudes, Skills, and Norms (Dissertation). University of California Davis, Davis, California.

Thomas A. Williams, Byron Chigoy, Jeff Borowiec, \& Brianne Glover. (2016). Methodologies Used to Estimate and Forecast Vehicle Miles Traveled (VMT) (No. PRC 15-40 F). Retrieved from Texas A\&M Transportation Institute website: https:// static.tti.tamu.edu/tti.tamu.edu/documents/PRC-15-40-F.pdf

Turner, Shawn, K., Pete. (2017). Using Mobile Device Samples to Estimate Traffic Volumes (No. MN/RC 2017-49). Retrieved from Minnesota Department of Transportation website: http:// mndot.gov/research/reports/2017/201749.pdf

Stanford University. (2019). Stanford Lands | Facts 2019. Retrieved June 5, 2019, from https://facts.stanford.edu/about/lands/

Wang, X., Khattak, A., \& Son, S. (2012). What Can Be Learned from Analyzing University Student Travel Demand? Transportation Research Record: Journal of the Transportation Research Board, 2322, 129-137. https://doi.org/10.3141/2322-14

Weible, B. (2016, July). Investigating the Impact of Skewed Pneumatic Traffic-Counting Tubes on Accuracy. 23.

World Business Council for Sustainable Development \& World Resources Institute. (2015). The Greenhouse Gas Protocol: A Corporate Accounting and Reporting Standard. Revised Edition. Washington DC. https://ghgprotocol.org/sites/default/ files/standards/ghg-protocol-revised.pdf. Accessed July 29, 2019.

Yiting Dai, Jill DeMatteis, \& Shelley Brock Roth. (2017). 2017 NHTS Weighting Report (p. 53). Westat.

Zhou, B., \& Kockelman, K. M. (2008). Self-selection in home choice: Use of treatment effects in evaluating relationship between built environment and travel behavior. Transportation Research Record, 2077(1), 54-61.

Zhou, J. (2012). Sustainable commute in a car-dominant city: Factors affecting alternative mode choices among university students. Transportation Research Part A: Policy and Practice, 46(7), 1013-1029. https://doi.org/10.1016/j. tra.2012.04.001 
Zmud, J., Lee-Gosselin, M., Munizaga, M., \& Carrasco, J. A. (2013). Transport Survey Methods. Retrieved from https://books.emeraldinsight.com/page/detail/transportsurvey-methods-by-johanna-zmudTransport-Survey-Methods/?k=9781781902875

Zolnik, E. J. (2007). Cost Attribution in Unlimited Access Transit Programs: Case Study on the UConn Prepaid Fare Program Failure. The Professional Geographer, 59(3), 365-377. https://doi.org/10.1111/j.1467-9272.2007.00619.x 


\section{ABOUT THE AUTHORS}

\section{TROY KAWAHARA}

Troy Kawahara is a master's candidate in Civil Engineering at California Polytechnic State University. He holds a bachelor's degree in Civil Engineering from California Polytechnic State University.

\section{BO LIU}

Bo Liu is currently pursuing a Ph.D. in urban planning at UCLA, with a focus on energy systems analysis and low-carbon growth planning. Prior to coming to UCLA, Bo worked at the Pacific Northwest National Laboratory and the New York State Assembly. He holds an M.S. in environmental science from SUNY College of Environmental Science and Forestry, an M.P.A. from Syracuse University, and a B.S. in environmental science from Beijing Normal University.

\section{ANURAG PANDE}

Anurag Pande is an Associate Professor of Civil Engineering at California Polytechnic State University. Dr. Pande received his B. Tech. in Civil Engineering from Indian Institute of Technology Bombay in Mumbai (India), and M.S. and Ph.D. in Civil Engineering from University of Central Florida (UCF). At Cal Poly he also serves as the faculty liaison for community engagement to foster partnerships between Cal Poly and nearby communities and non-profit organizations.

\section{CALVIN THIGPEN}

Calvin Thigpen recently joined Lime as a policy research manager. Prior to that, he was a post-doctoral researcher at Arizona State University. Calvin holds a Ph.D. in Transportation Technology and Policy from UC Davis, where he administered the 2014-15 UC Davis Campus Travel Survey (CTS), an annual survey of faculty, staff, and students.

\section{CAROLE TURLEY VOULGARIS}

Carole Turley Voulgaris is an Assistant Professor of Civil Engineering at California Polytechnic State University. She holds a Ph.D. in Urban Planning from UCLA, an M.B.A. from the University of Notre Dame, and bachelor's and master's degrees in civil engineering from Brigham Young University. 


\section{PEER REVIEW}

San José State University, of the California State University system, and the Mineta Transportation Institute (MTI) Board of Trustees have agreed upon a peer review process required for all research published by MTI. The purpose of the review process is to ensure that the results presented are based upon a professionally acceptable research protocol. 


\section{Hon. Norman Y. Mineta}

\section{MTI BOARD OF TRUSTEES}

Founder, Honorable Norman Mineta (Ex-Officio)

Secretary (ret.),

US Department of Transportation

Chair, Grace Crunican (TE 2019)

General Manager

Bay Area Rapid Transit District (BART)

Vice Chair,

Abbas Mohaddes (TE 202I)

President \& $\mathrm{COO}$

Econolite Group Inc.

Executive Director,

Karen Philbrick, Ph.D.

(Ex-Officio)

Mineta Transportation Institute

San José State University

\section{Richard Anderson}

(Ex-Officio)

President \& CEO

Amtrak

Laurie Berman (Ex-Officio)

Director

California Department of

Transportation (Caltrans)
David Castagnetti (TE 202I)

Co-Founder

Mehlman Castagnetti

Rosen \& Thomas

Maria Cino (TE 202I)

Vice President

America \& U.S. Government

Relations Hewlett-Packard Enterprise

Donna DeMartino (TE 202I)

General Manager \& CEO

San Joaquin Regional Transit District

Nuria Fernandez* (TE 2020)

General Manager \& CEO

Santa Clara Valley

Transportation Authority (VTA)

John Flaherty (TE 2020)

Senior Fellow

Silicon Valley American

Leadership Form

Rose Guilbault (TE 2020)

Board Member

Peninsula Corridor

Joint Powers Board
Ian Jefferies (Ex-Officio)

President \& CEO

Association of American Railroads

Diane Woodend Jones (TE 2019)

Principal \& Chair of Board

Lea + Elliott, Inc.

Will Kempton (TE 2019)

Retired

Jean-Pierre Loubinoux

(Ex-Officio)

Director General

International Union of Railways (UIC)

Bradley Mims (TE 2020)

President \& CEO

Conference of Minority

Transportation Officials (COMTO)

Jeff Morales (TE 2019)

Managing Principal

InfraStrategies, LLC

Dan Moshavi, Ph.D. (Ex-Officio)

Dean, Lucas College and

Graduate School of Business

San José State University
Takayoshi Oshima (TE 202I)

Chairman \& CEO

Allied Telesis, Inc.

Paul Skoutelas (Ex-Officio)

President \& CEO

American Public Transportation

Association (APTA)

Dan Smith (TE 2020)

President

Capstone Financial Group, Inc.

Beverley Swaim-Staley

(TE 2019)

President

Union Station Redevelopment

Corporation

Larry Willis (Ex-Officio)

President

Transportation Trades

Dept., AFL-CIO

Jim Thymon (Ex-Officio)

Executive Director

American Association of

State Highway and Transportation

Officials (AASHTO)

[Retiring $|2 / 3| / 20 \mid 8$ ]

$(\mathrm{TE})=$ Term Expiration

$*$ = Past Chair, Board of Trustees

\section{Directors}

Karen Philbrick, Ph.D.

Executive Director

Hilary Nixon, Ph.D.

Deputy Executive Director

Asha Weinstein Agrawal, Ph.D.

Education Director

National Transportation Finance

Center Director

Brian Michael Jenkins

National Transportation Security

Center Director

\section{Research Associates Policy Oversight Committee}

Jan Botha, Ph.D.

Civil \& Environmental Engineering

San José State University

Katherine Kao Cushing, Ph.D.

Enviromental Science

San José State University

Dave Czerwinski, Ph.D.

Marketing and Decision Science

San José State University
Frances Edwards, Ph.D.

Political Science

San José State University

Taeho Park, Ph.D.

Organization and Management

San José State University

Christa Bailey

Martin Luther King, Jr. Library

San José State University

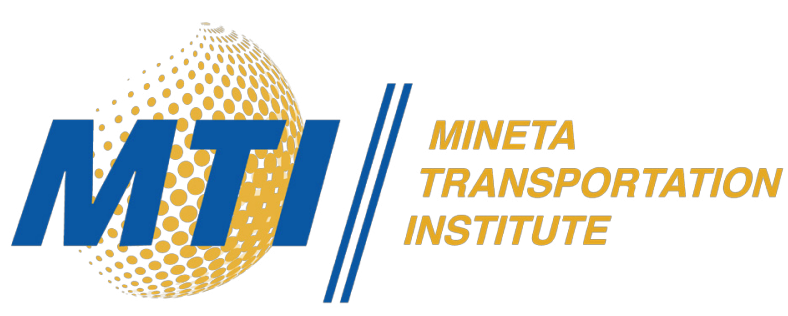

